\title{
Recognition and Sensing of Chiral Organic Molecules by Chiral Porphyrinoids: A Review
}

\author{
Gabriele Travagliante, Massimiliano Gaeta *(D), Roberto Purrello (D) and Alessandro D’Urso *(D) \\ Dipartimento di Scienze Chimiche, Università degli Studi di Catania, Viale Andrea Doria 6, 95125 Catania, Italy; \\ travagliantegab@gmail.com (G.T.); rpurrello@unict.it (R.P.) \\ * Correspondence: gaetamassimiliano@libero.it (M.G.); adurso@unict.it (A.D.)
}

check for updates

Citation: Travagliante, G.; Gaeta, M. Purrello, R.; D'Urso, A. Recognition and Sensing of Chiral Organic Molecules by Chiral Porphyrinoids: A Review. Chemosensors 2021, 9, 204. https: / / doi.org/10.3390/

chemosensors 9080204

Academic Editors: Victor Borovkov, Riina Aav, Roberto Paolesse,

Manuela Stefanelli, Donato Monti and Marco Frasconi

Received: 6 July 2021

Accepted: 31 July 2021

Published: 3 August 2021

Publisher's Note: MDPI stays neutral with regard to jurisdictional claims in published maps and institutional affiliations.

Copyright: (c) 2021 by the authors. Licensee MDPI, Basel, Switzerland. This article is an open access article distributed under the terms and conditions of the Creative Commons Attribution (CC BY) license (https:// creativecommons.org/licenses/by/ $4.0 /)$.

\begin{abstract}
Porphyrinoids are extremely attractive for their electronic, optical, and coordination properties as well as for their versatile substitution at meso/ $\beta$-positions. All these features allow porphyrinoids to behave as chiroptical hosts for chiral recognition by means of non-covalent interactions towards chiral guests. Over the years, chiral discrimination of chiral molecules such as amino acids, alcohols, amines, hydroxy-carboxylic acids, etc. has aroused the interest of the scientific community. Hence, this review aims to report on the progress to date by illustrating some relevant research regarding the chiral recognition of a multitude of chiral organic guests through several chiral monoand bis-porphyrins via different spectroscopic techniques.
\end{abstract}

Keywords: chirality; chiral recognition; sensing; porphyrin; chiral guest; circular dichroism

\section{Introduction}

Two or more molecules, able to non-covalently interact and to display binding-site complementarity, may exhibit molecular recognition [1,2]. In this respect, the chiral recognition is a specific process in which a host molecule selectively binds, through supramolecular forces (e.g., hydrogen bonding, metal coordination, hydrophobic effects, van der Waals forces, $\pi-\pi$ and/or electrostatic interactions) to a precise enantiomer of the guest molecule compared with mirror stereoisomer [3-11]. Nevertheless, this latter phenomenon represents a key process in a wide range of chemical systems and biological occurrences in the natural world [12-17]. In this context, porphyrins, owing to their (i) extensive electron conjugation, (ii) fascinating spectral and photophysical properties, along with (iii) the facile metal coordination and functionalization at meso/ $\beta$-positions [18-20], can be successfully employed as ideal receptors to recognize a large variety of guests [21,22]. For this reason, porphyrinoids and related derivatives find numerous applications in the literature, ranging from energy transfer phenomena and catalysis to oxygen transport and biological and supramolecular self-assembled systems [23-28].

Chiral porphyrins and metalloporphyrins are particularly well suited for molecular recognition and optical resolution since they can be useful for the determination of absolute configuration, enantiomeric resolution, and enantiomeric excess of chiral molecules [29-36]. Furthermore, they can mimic biomolecular recognition in biological and biochemical processes [37]. Monomeric porphyrinoids can exhibit two sorts of chirality: (i) extrinsic chirality, which occurs when chiral substituents are covalently bonded to the macrocycle ring [38], and (ii) intrinsic chirality, in which achiral substituents are arranged along a chiral axis or on a chiral plane to the porphyrin ring $[16,39,40]$. In addition, chiral dimeric and multimeric porphyrins can be achieved by means of a chiral bridge between chiral or achiral porphyrin rings [18].

Although several studies have reported the opportunity to discriminate numerous guests by using both symmetric and asymmetric porphyrin derivatives [10,41-46], this review exclusively focuses on chiral porphyrinoids as probes for recognition and sensing of chiral organic molecules, with particular regard to amino acids, their ester-derivative 
amines, alcohols, carboxylic acids, and their derivatives, as well as some chiral aromatic compounds-ruling out, however, the corresponding achiral counterparts.

The major advantage of using chiral porphyrins over achiral ones is because of the formation of host-guest diastereomeric complexes that present different physical and chemical properties and can be easily monitored by conventional spectroscopic methods, such as UV/Vis, fluorescence, ${ }^{1} \mathrm{H}$ NMR, and circular dichroism [47]. Noteworthy, among several chiral molecules, as reported in the literature, special attention is given to amino acid guests. In fact, amino acids are fundamental bioactive molecules broadly employed in several chemical and pharmaceutical fields [48]. Additionally and more remarkable, the chiral discrimination of enantiomers from amino acids constitutes a crucial step in better investigating the origin of "homochirality" in biological systems, as well as in developing interesting chiral devices for technological applications [49-51]. For instance, in the agrifood field, D- and L-amino acid profiles can give important information to reveal food adulteration [52,53], food quality, and the nutritional value of foods [54]. Nevertheless, chiral discrimination of other chiral organic guests has been taken into account.

\section{Chiral Recognition of Amino Acids and Their Esters}

\subsection{Monomeric Porphynoids}

The pioneering research concerning the chiral recognition of amino acids and corresponding methyl ester derivatives was from Professor Y. Kuroda's group. In fact, between 1993 and 1995, they reported a systematic synthesis of several chiral porphyrinoids to discriminate amino acid methyl esters (Figure 1a-d, I-IV) [55-58]. In fact, in amino acids, both amino and carboxyl moieties are expected to behave as sites for hydrogen bonding and electrostatic interactions (Figure 1e), whilst the $\alpha$-R group may form further binding sites (i.e., van der Waals forces, hydrophobic interactions, steric hindrance). Thus, since an effective chiral recognition mechanism demands at least a spatially oriented three (or two)-point interaction, amino acids can appear as suitable guest models for the molecular recognition processes. Nevertheless, if the host system contains a metal ion, a coordination interaction may occur between the guest amino acid and the host system. As a consequence, Kuroda et al., designed Zinc(II)-porphyrin derivatives having two (Figure 1c, III) or three (Figure 1d, IV) recognition elements (i.e., metal coordination, hydrogen bond donor, and hydrogen bond acceptor-or steric repulsion groups) in order to realize a convergent chiral recognition pocket (Figure 1f) [55-58]. In particular, chiral doubly bridged free-base tetraarylporphyrins (Figure 1a,b I-II), chiral Zinc(II) porphyrins with three arms (5, 10, 15-meso positions, III) and Zinc(II) with two functional arms (5, 15-meso positions, IV) were synthesized as racemic mixtures and resolved by chiral HPLC. As a result, the association constants were determined in halogenated solvents (e.g., chloroform or dichloromethane) by the UV/Vis titration method, proving different binding affinity depending on the sort of amino acid esters used and their own chirality.

Another example of chiral recognition of amino acid esters was reported in 2001 by Zhu et al. [59]. They synthesized chiral Zn(II)-porphyrin-amino acid derivative porphyrin (Figure 2a, V) to discriminate in dichloromethane and at room conditions, Dor L-enantiomers from alanine, phenylalanine, leucine, and isoleucine methyl esters by $\mathrm{UV} /$ Vis spectrophotometric titrations. More striking, different dichroic behavior is observed throughout the formation of porphyrin/amino acid ester complexes, providing as well, a simple spectroscopic tool to recognize the original chirality of the amino acid guest used. Indeed, in the CD spectra, a single negative CD band at $425 \mathrm{~nm}$ is shown when the chiral $\mathrm{Zn}$ (II) porphyrin $\mathbf{V}$ is alone (Figure $2 \mathrm{~b}$ ). Thus, by adding the L-enantiomers of methyl esters of amino acids, a negative $\mathrm{CD}$ band is displayed; however, it is very similar in shape and position to the band of $\mathrm{Zn}$ (II)-porphyrin $\mathbf{V}$ alone. Contrarily, the complex with the corresponding D-enantiomer exhibits bisignate CD signals with positive CD bands at $\sim 435 \mathrm{~nm}$ and negative at $\sim 428 \mathrm{~nm}$ (Figure 2b). The mechanism leading to such CD spectra still remains ambiguous. A possible explanation may be inferred from a major stability of the D-enantiomers onto the porphyrin plane [59]. 

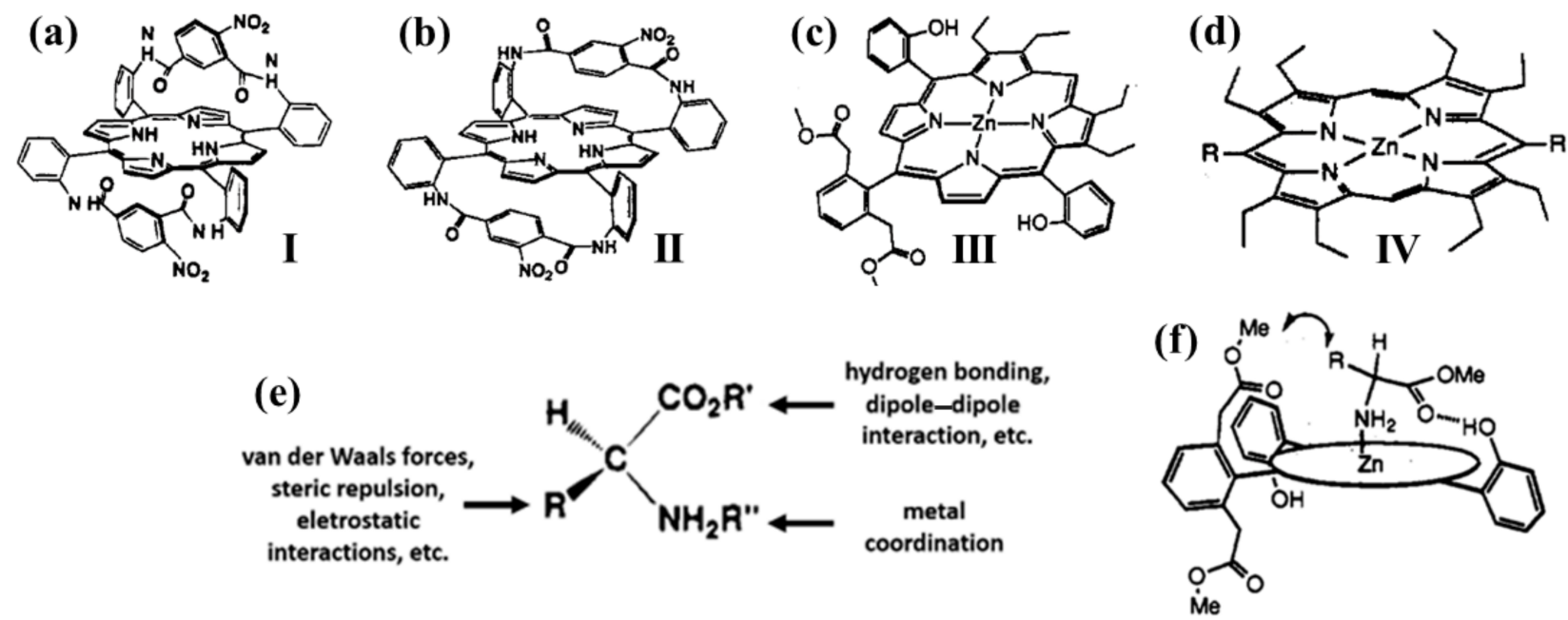

Figure 1. (a-d) Structure (I-IV) of chiral porphyrins used, from Kuroda et al. Notable, the chirality of IV is brought by the R group; (e) Sites of amino acids able to form non-covalent interactions; (f) Schematic model of non-covalent interactions between an amino acid and the chiral porphyrin pocket sketched from structure III. Figure 1a,e adapted with permission from reference [56]; published by American Chemical Society 1995. Figure $1 \mathrm{~b}$ adapted with permission from reference [55]; published by John Wiley and Sons 2003. Figure 1c,f adapted with permission from reference [57]; published by American Chemical Society 1994. Figure 1d adapted with permission from reference [58]; published by American Chemical Society 1993.

(a)

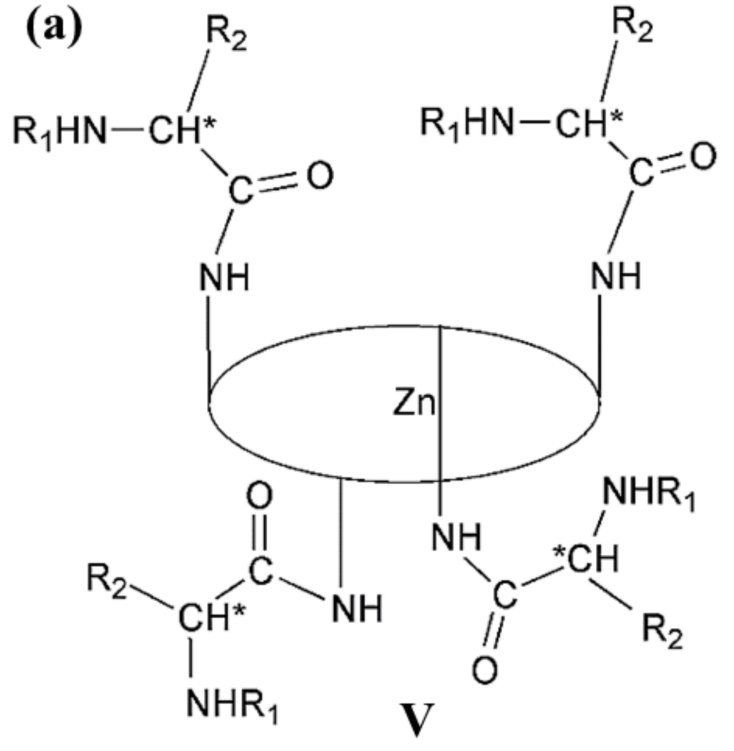

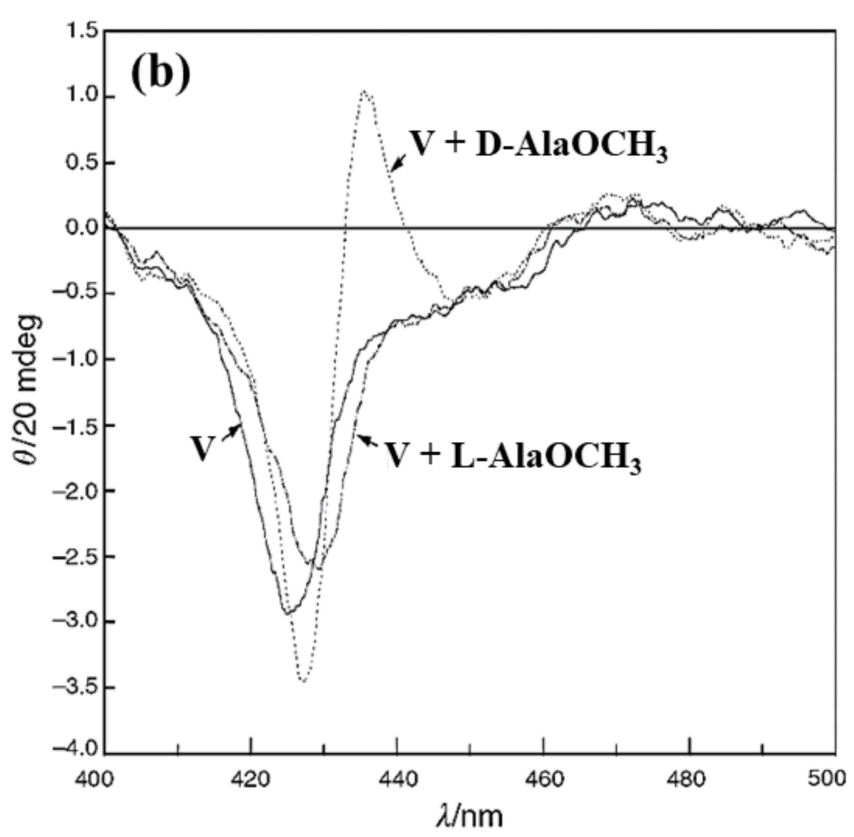

Figure 2. (a) Schematic of chiral porphyrin $\mathbf{V}$ synthesized by Zhu et al. The stereogenic centres are indicated by an asterisk $\left(^{*}\right)$; (b) CD spectra of chiral porphyrin $\mathbf{V}$ alone and in presence of $\mathrm{L}^{-\mathrm{AlaOCH}_{3}}$ and $\mathrm{D}-\mathrm{AlaOCH}_{3}$ in dichloromethane at $298 \mathrm{~K}$. Adapted with permission from reference [59]; published by Royal Society of Chemistry 1987.

In the same period, several biconcave C4-symmetric (pyridino-(CO)-Ru(II)-porphyrin and iodo-Rh(III)-porphyrin) and D4-symmetric ( $\mathrm{Zn}(\mathrm{II})$-porphyrin, dioxo-Ru(VI)-porphyrin) metalloporphyrins with a rigid framework (Figure $3 a$, VI) were investigated by Kräutler et al. [60,61]. These biconcave metalloporphyrins proved to be useful as chiral ${ }^{1} \mathrm{H}$ NMR shift agents for a wide number of chiral organic compounds and chiral nonpolar fullerene derivates. The CD spectrum of biconcave $\mathrm{Zn}$ (II)-porphyrin VI has positive CD bands at $\sim 408 \mathrm{~nm}, \sim 300 \mathrm{~nm}$, and $\sim 248 \mathrm{~nm}$ and negative CD bands at $\sim 317 \mathrm{~nm}$ 
and $283 \mathrm{~nm}$ (Figure 3b). Paramagnetic Co(II)-porphyrin VI showed significant chiral shifts for compounds having dinitrile moieties or 2,6-di-tert-butylanthracene and other chiral nonpolar fullerene adducts. On the contrary, diamagnetic $\mathrm{Zn}$ (II)-porphyrin and iodo-Rh(III)-porphyrin revealed to be the most versatile NMR shift agents for several chiral organic molecules, such as chiral alcohols $(( \pm) 1-(9$-anthryl)-2,2,2-trifluoroethanol) (Figure $3 c)$, amines $(( \pm) \alpha$-phenylethylamine), esters $(( \pm)$ menthyl acetate), and carboxylic acids $(( \pm) \alpha$-methoxyphenylacetic acid $)$.
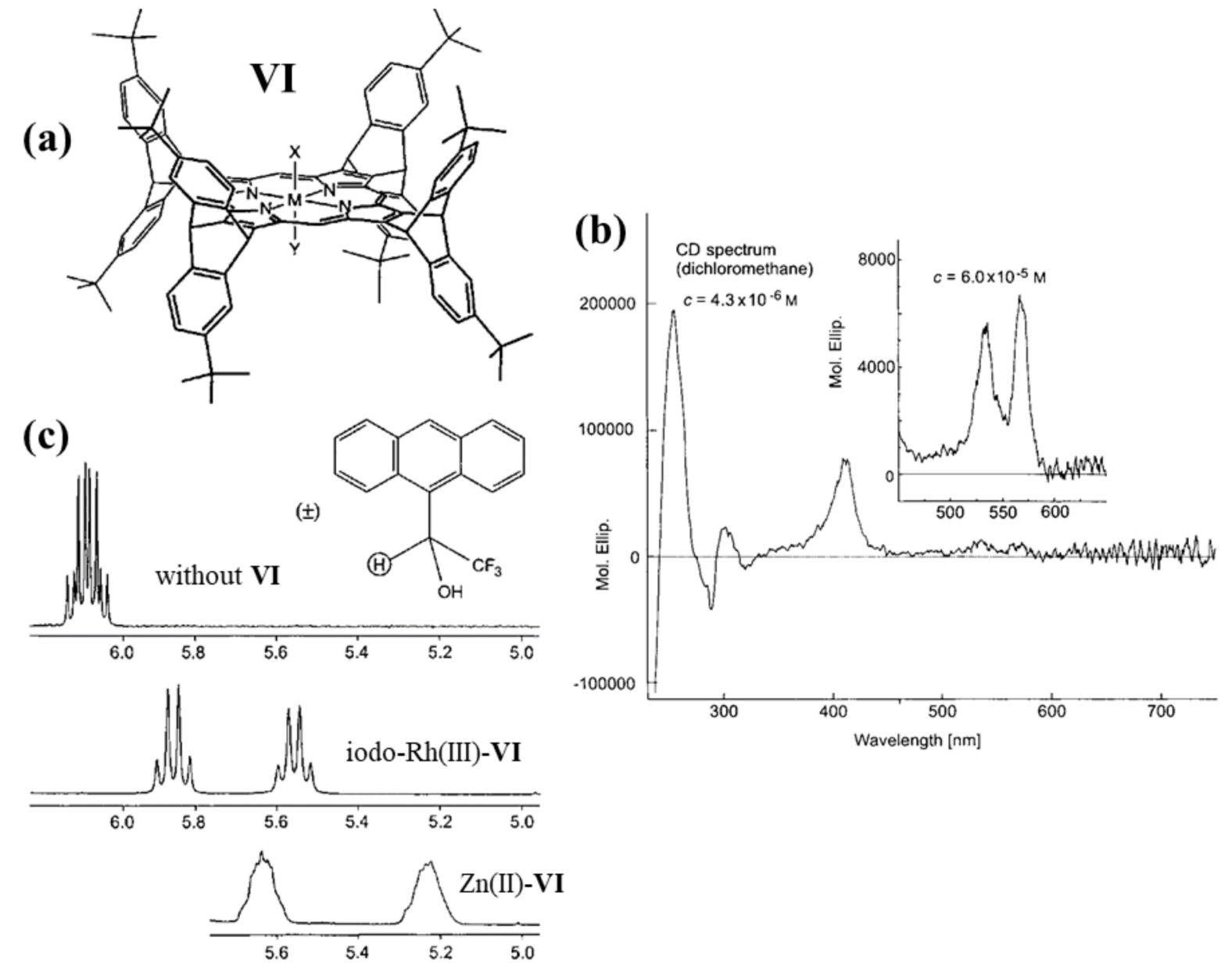

Figure 3. (a) Structure of biconcave metalloporphyrins with a rigid framework VI; (b) CD spectra of biconcave Zn(II)porphyrin VI in dichloromethane; (c) ${ }^{1} \mathrm{H}$ NMR shift experiments in $\mathrm{C}_{6} \mathrm{D}_{6}$ of racemic 1-(9-anthryl)-2,2,2-trifluoroethanol in the absence (top) and presence (middle and bottom) of chiral bis-metalloporphyrins iodo-Rh(III)-porphyrin VI and Zn(II)-porphyrin VI. Adapted with permission from reference [61]; published by John Wiley and Sons 2001.

A few years later, in 2004, Imai et al., reported the first study regarding the chiral recognition of amino acids and dipeptides in water at room temperature [62]. They synthesized water-soluble chiral Zn(II)-porphyrin derivative (Figure 4a, VII) with C2 symmetry, prepared as a racemic mixture and resolved by chiral HPLC method. The CD spectra of both enantiomers show specular bisignate couplets in the porphyrin Soret region around $425 \mathrm{~nm}$ and $442 \mathrm{~nm}$ (Figure $4 \mathrm{~b}$ ). The two Zinc(II)-porphyrin VII enantiomers showed chiral selectivity for L-enantiomers of amino acids and dipeptides by UV/Vis titration method in an aqueous solution. According to Kuroda's observations, the chiral recognition mechanism suggested by the authors consists of three types of interaction: coulombic, coordination, and steric repulsion, as illustrated in Figure 4c. 


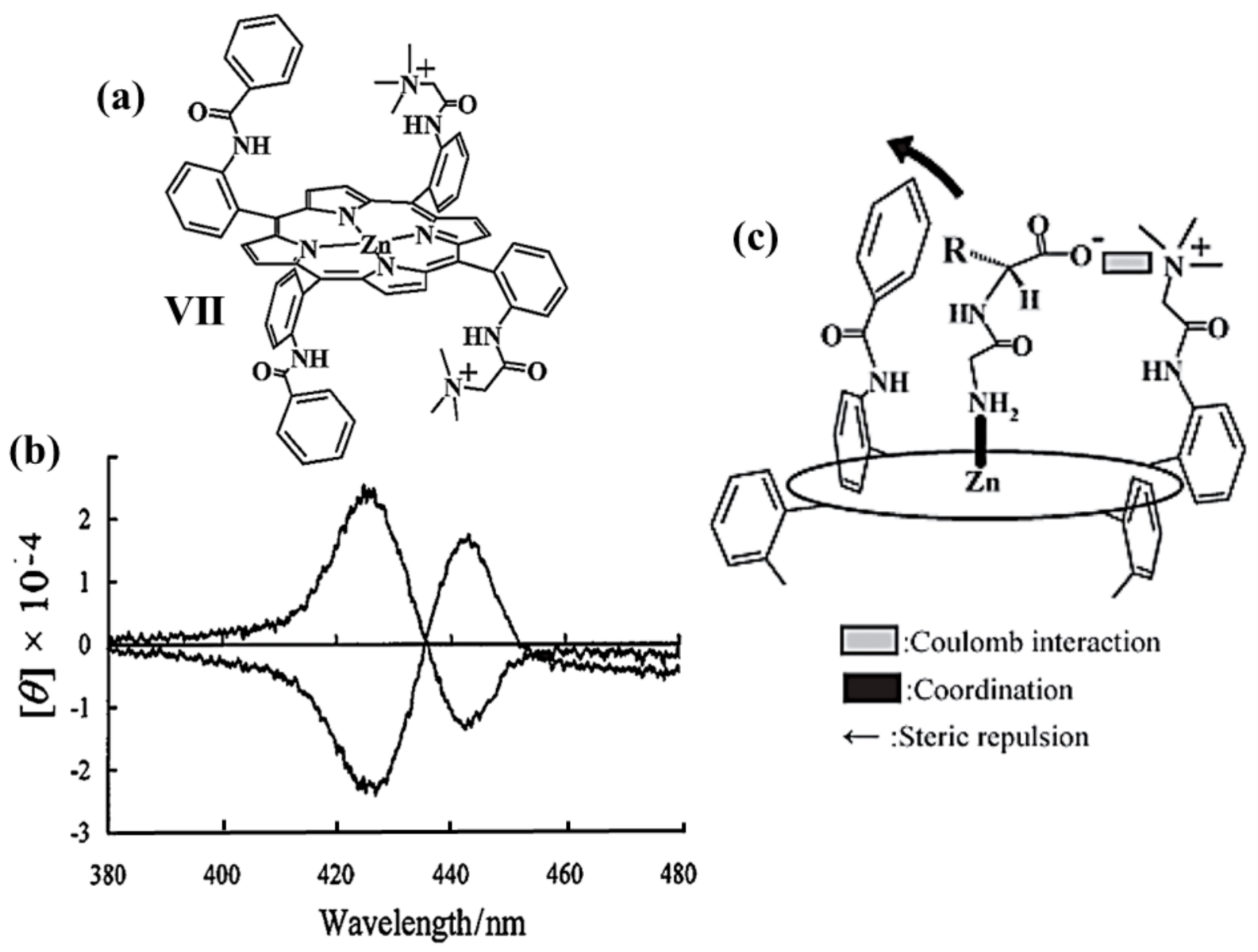

Figure 4. (a) Structure of chiral Zn(II)-porphyrin derivative VII; (b) CD spectra of separated enantiomers of chiral porphyrin VII in water $(\mathrm{pH}=10.4$, ionic strength $=0.02)$; (c) Proposed chiral recognition mechanism: molecular interactions between an enantiomer of chiral $\mathrm{Zn}(\mathrm{II})$-porphyrin VII with D-amino acids. Adapted with permission from reference [62]; published by American Chemical Society 2004.

The incorporation of a chiral porphyrin (Figure 5a, VIII) into the mesoporous molecular sieves SBA-15 for chiral recognition of small amino acids was investigated in 2006 by Wang et al. [63]. The resultant material was analyzed by circular dichroism spectroscopy, demonstrating $\mathrm{CD}$ signals very different compared with those of the chiral porphyrin alone in solution (Figure $5 \mathrm{~b}$ ). The authors explained such difference in terms of intermolecular interaction of chiral porphyrin VIII with the OH- groups in the channel of SBA-15. Moreover, they demonstrated by UV/Vis and CD spectroscopy that the composite material (SBA-15/porphyrin) has a higher affinity for D-alanine than the L-enantiomer through the mixing in the water of the composite mesoporous materials with the related chiral amino acids at room temperature. Noteworthy, in comparison with L-alanine, the D-enantiomer is more tightly absorbed into the channel and onto the surface of the mesoporous material. This research provides a feasible model to overcome the tedious preparation in organic solvents, along with the weak solubility of some amino acids in an organic environment, facilitating the host-guest separation as well.

A chiral Zn(II)-porphyrin derivative with C1 symmetry (Figure 6a, IX) was reported by Yang et al., in 2013 [18]. Such chiral system showed enantioselectivity for a pair of amino acid esters (L- and D-Phe-OMe). The UV/Vis spectrophotometric titrations were performed to determine the association constants in chloroform, suggesting scarce enantioselectivity for the R-porphyrin IX against L-Phe-OMe compared with its chiral counterpart. Furthermore, chiral discrimination of porphyrin-amino ester (Figure 6b) by using ${ }^{1} \mathrm{H}$ NMR spectroscopy was investigated. The authors proposed a formation of a host-guest complex with two types of interactions: coordination via $\mathrm{NH}_{2}-\mathrm{Zn}$ and hydrogen 
bonding of $\mathrm{C}=\mathrm{O} \cdots \mathrm{HO}$ (Figure $6 \mathrm{~b}$ ). These interactions induce the loss of motion freedom of the host molecules, resulting in the resolution of NMR signals.

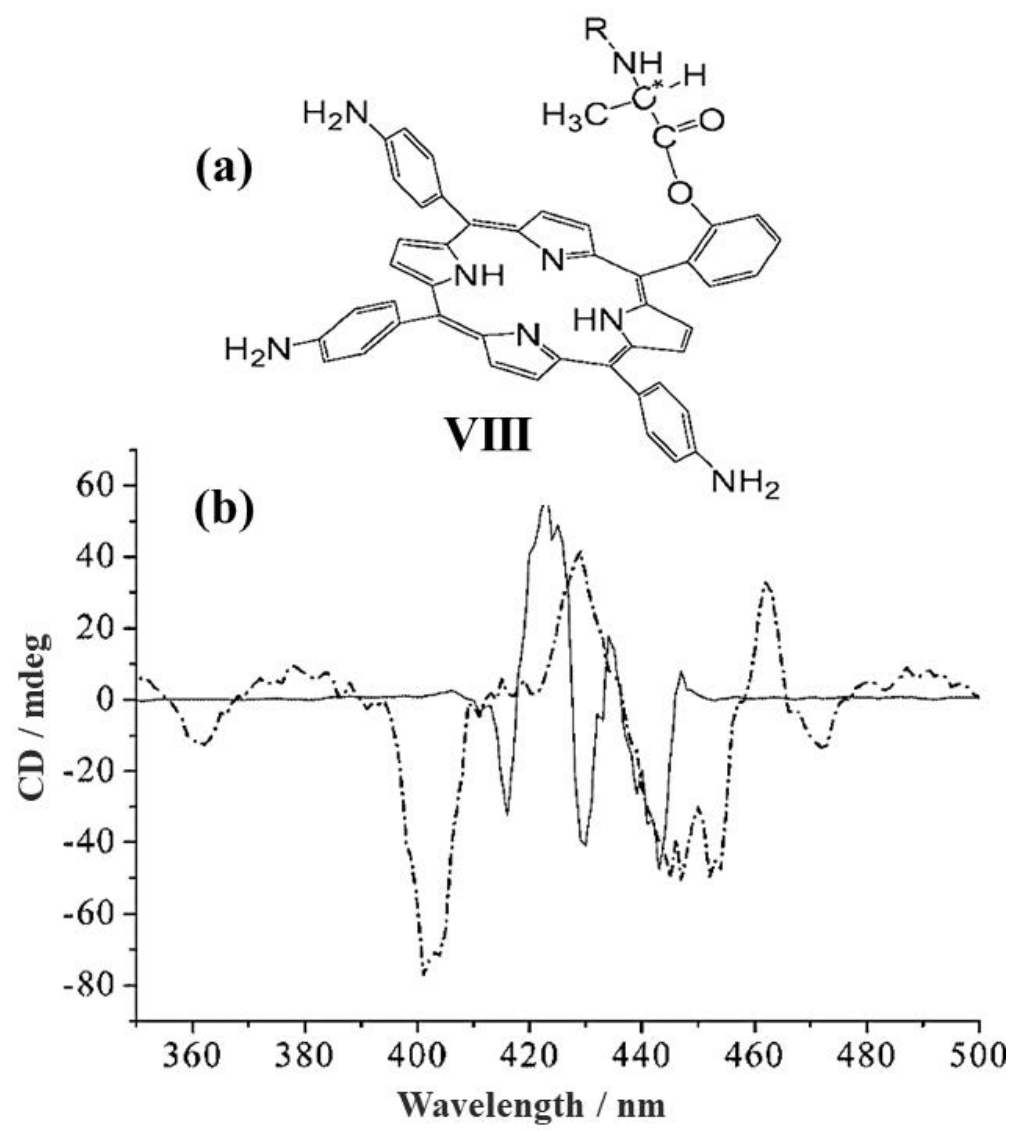

Figure 5. (a) Structure of the chiral porphyrin VIII $(\mathrm{R}=\mathrm{Boc})$; (b) CD spectra of the chiral porphyrin VIII in chloroform (solid line), SBA-15/porphyrin in solid-state (dash-dotted line). Adapted with permission from reference [63]; published by John Wiley and Sons 2006.

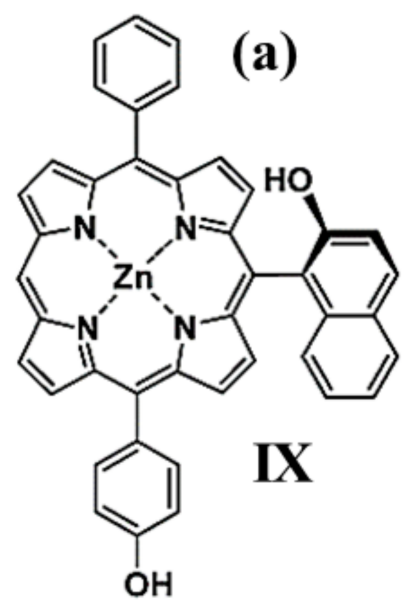

R-porphyrin (b)

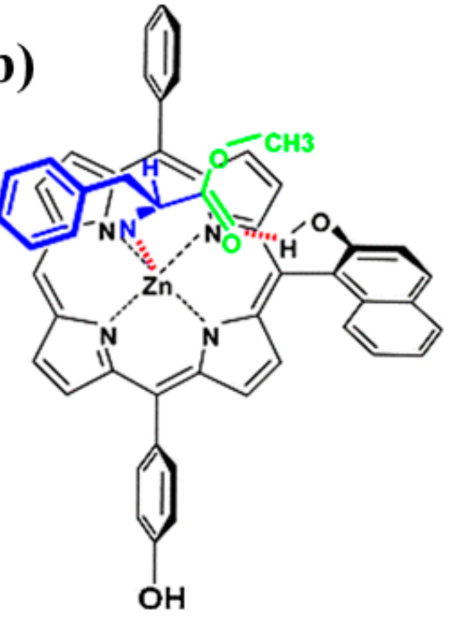

R-porphyrin / L-Phe-OMe

Figure 6. (a) Structure of the chiral Zn(II)-porphyrin IX synthesized by Yang et al.; (b) Interactions between R-enantiomer of the chiral porphyrin IX with L-Phe-OMe. Adapted with permission from reference [18]; published by American Chemical Society 2013. 


\subsection{Bis-Porphyrin Systems and Porphyrin-Tweezers}

The first work on chiral recognition based on bis-porphyrin systems dates back to 1995, reported by Crossley et al. [64]. They prepared Troger's base analogue chiral porphyrin dimer (Figure 7a, X) for chiral recognition of methyl and benzyl esters of histidine and lysine amino acids [65]. The bis-porphyrin was prepared as a racemic mixture and resolved by the chiral HPLC technique. The resolved enantiomer pairs have a C2 symmetry, and they display specular CD spectra with a bisignate couplet in the Soret band region (Figure $7 \mathrm{~b}$ ). NMR spectroscopy was used to investigate the affinity of the bis-porphyrin towards chiral amino acid derivates: high affinity was shown for the histidine methyl and benzyl esters (calculated enantiomeric excess up to $80-86 \%$ ) and for lysine benzyl ester (calculated enantiomeric excess up to $48 \%$ ) in deuterated chloroform (Figure 7c).
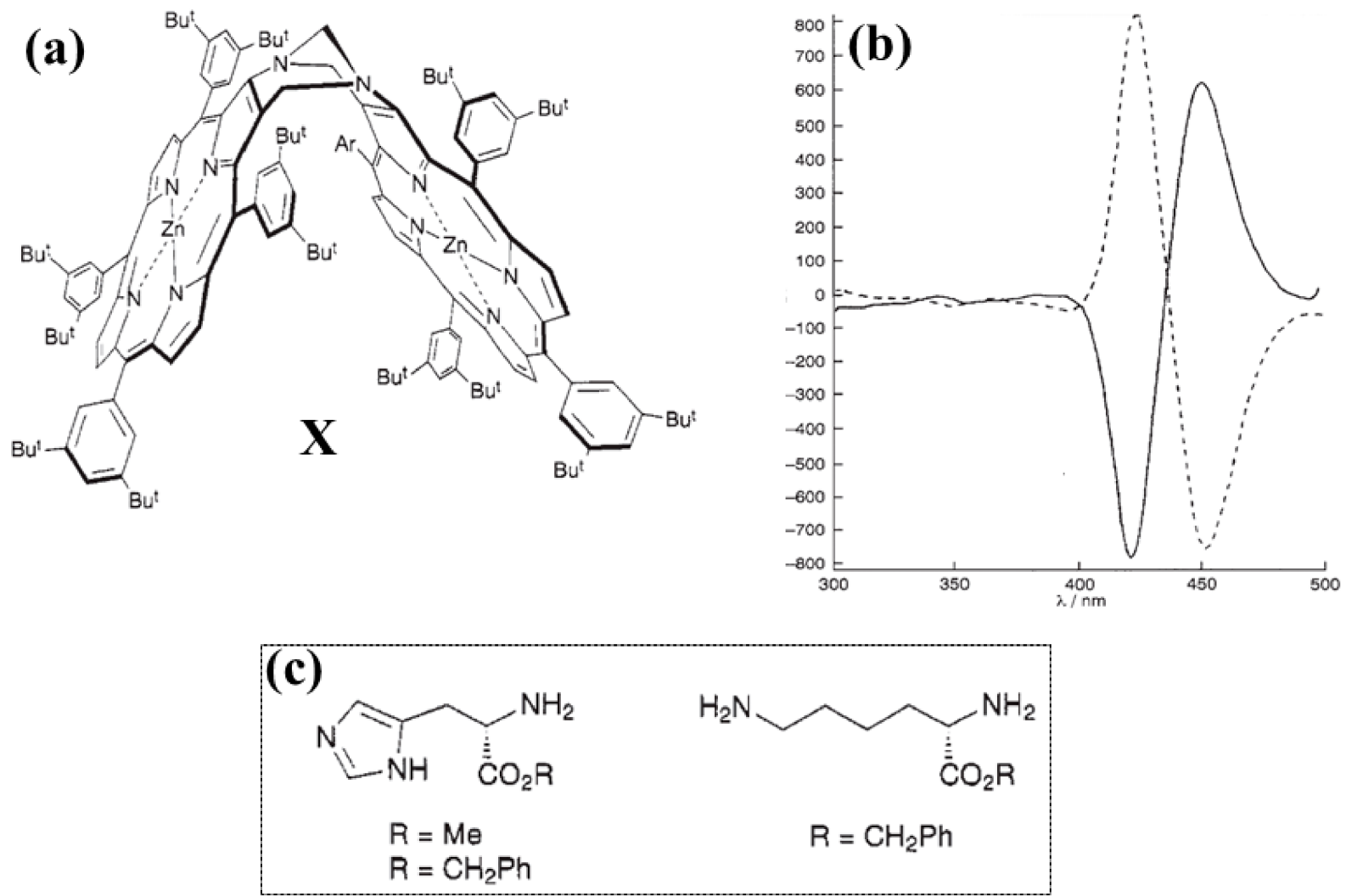

Figure 7. (a) Structure of the chiral bisporphyrin $\mathbf{X}$; (b) CD spectra of the enantiomers of $\mathrm{Zn}$ (II) bis-porphyrin $\mathbf{X}$ in chloroform; (c) Structures of histidine methyl and benzyl esters (on the left) and lysine benzyl ester (on the right). Adapted with permission from reference [65]; published by Royal Society of Chemistry 1995.

In 2014, Dolensky et al., reported a flexible chiral Troger's base cobalt-bis-porphyrin derivate (Figure 8a, XI) as a possible enantioselective receptor of several amino acid methyl esters [66]. The bis-porphyrin $\mathbf{X I}$ was prepared as a racemic mixture and resolved by chiral HPLC. The resolved enantiomers showed mirror-image CD spectra with a bisignate couplet in the Soret band region (Figure 8b). UV/Vis and CD titration experiments were performed for complexation studies, demonstrating that the bis-porphyrin owns the highest enantioselectivity for lysine methyl ester, with a binding constant ratio L-/D-isomers around $\sim 2$. The high flexibility of bis-porphyrin after interaction with a guest allows for the reorientation as a function of the structure and chirality of the guest; therefore, the sign of the Cotton effect in ECD spectra can reflect the structure and chirality of the guest, as observed for $\mathrm{Lys}_{-} \mathrm{OCH}_{3}$ enantiomers (Figure 8c). 


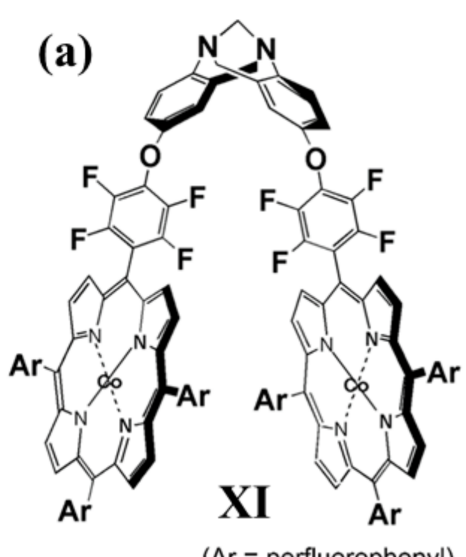

$(\mathrm{Ar}=$ perfluorophenyl)
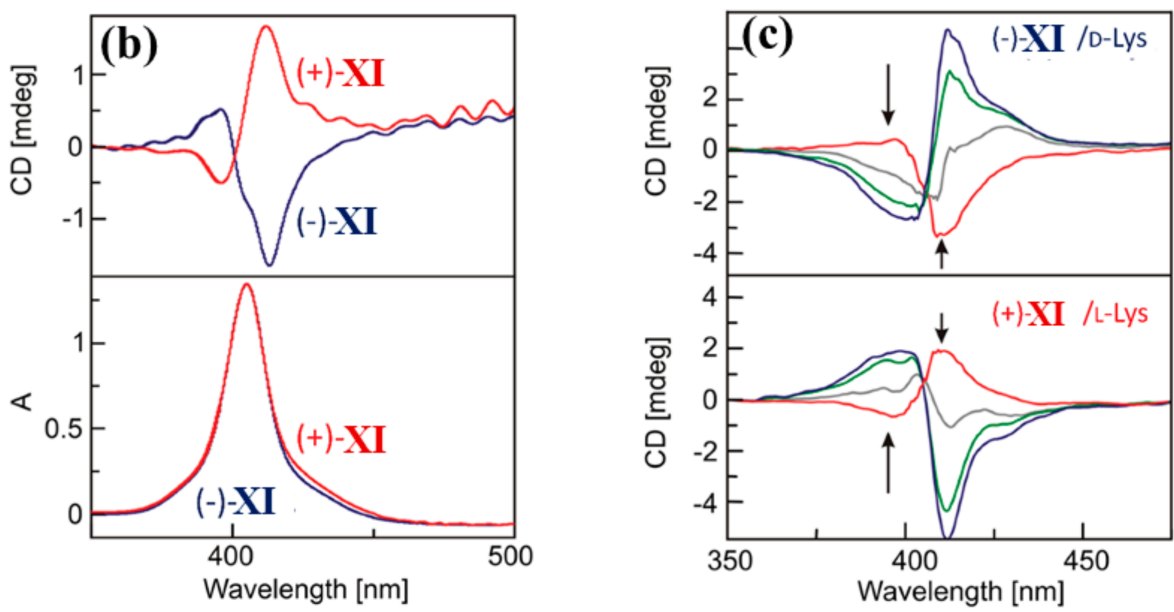

Figure 8. (a) Structure of cobalt-bis-porphyrin derivate XI; (b) CD (top) and UV/Vis (bottom) spectra of the enantiomers of XI in dichloromethane; (c) Titration CD spectra of XI stereoisomers with an increasing amount of D- and L-lysine methyl ester. Adapted with permission from reference [66]; published by John Wiley and Sons 2014.

Seo et al., in 2018, described a chiral metalloporphyrin tweezer bridged by a peptoid helix (Figure 9a, XII) for chiral recognition of asymmetric and symmetric guests [67]. In particular, the chiral XII was first employed to discriminate a wide range of achiral dinitrogen compounds (e.g., ethylenediamine, 1,4-diaminobutane, 1,6-diaminohexane, pyridine, 4,4'-dipyridyl, 4,4'-trimethylenedipyridine, piperidine, 4,4'-bipiperidine, $4,4^{\prime}$ trimethylenedipiperidine), pointing out minor, but at the same time, discernable spectroscopic changes in the host-guest complexes depending on the length and basicity of the achiral guests used. Noteworthy, the porphyrin tweezer XII also showed a high ability to recognize enantiomers of lysine methyl ester due to the formation of diastereomeric complexes underlined by a clear and distinct $C D$ couplet in comparison with the abovementioned achiral diamines. Indeed, the CD spectra of the uncomplexed porphyrin tweezer displayed a bisignate signal $(-/+)$ with a negative band around $420 \mathrm{~nm}$ and a positive band around $430 \mathrm{~nm}$ (Figure $9 \mathrm{~b}$ ). The addition of an increasing amount of D-lysine methyl ester does not produce significant changes in the $\mathrm{CD}$ spectra, exhibiting the same bisignate signal $(-/+)$, except for lower intensity and a slightly red-shift (Figure $9 \mathrm{~b}$ ). On the contrary, when L-lysine methyl ester is added (equivalence higher than 1) an " $M$-shape" CD signal occurs (Figure 9b). Noteworthy, at the highest amounts of L- and D-lysine methyl ester, the $\mathrm{CD}$ spectra did not show a mirror image signal (Figure 9c) supporting the formation of diastereomeric complexes.

Recently, a novel chiral tartaric acid amide linked zinc bis-porphyrinate (Figure 10a, XIII) was investigated for enantioselectivity recognition of chiral amino acid esters by Wang et al. [68]. UV/Vis titration studies in dichloromethane revealed that the chiral bis-porphyrin XIII owns great enantioselectivity towards amino acid esters (Figure 10b), with the highest ratio of 8.4 observed for D-/L-phenylalanine ethyl ester. The CD spectrum of chiral bis-porphyrin showed a bisignate couplet with a positive band around $415 \mathrm{~nm}$ and a negative band around $425 \mathrm{~nm}$ (Figure 10c). By adding L- amino acid ester, the sign of the bisignate couplet is maintained, but it is red-shifted to lower intensity. On the other hand, the presence of D-amino acid ester reverses the sign of the couplet, providing an interesting chiral sensing tool in organic solution (Figure 10c). 

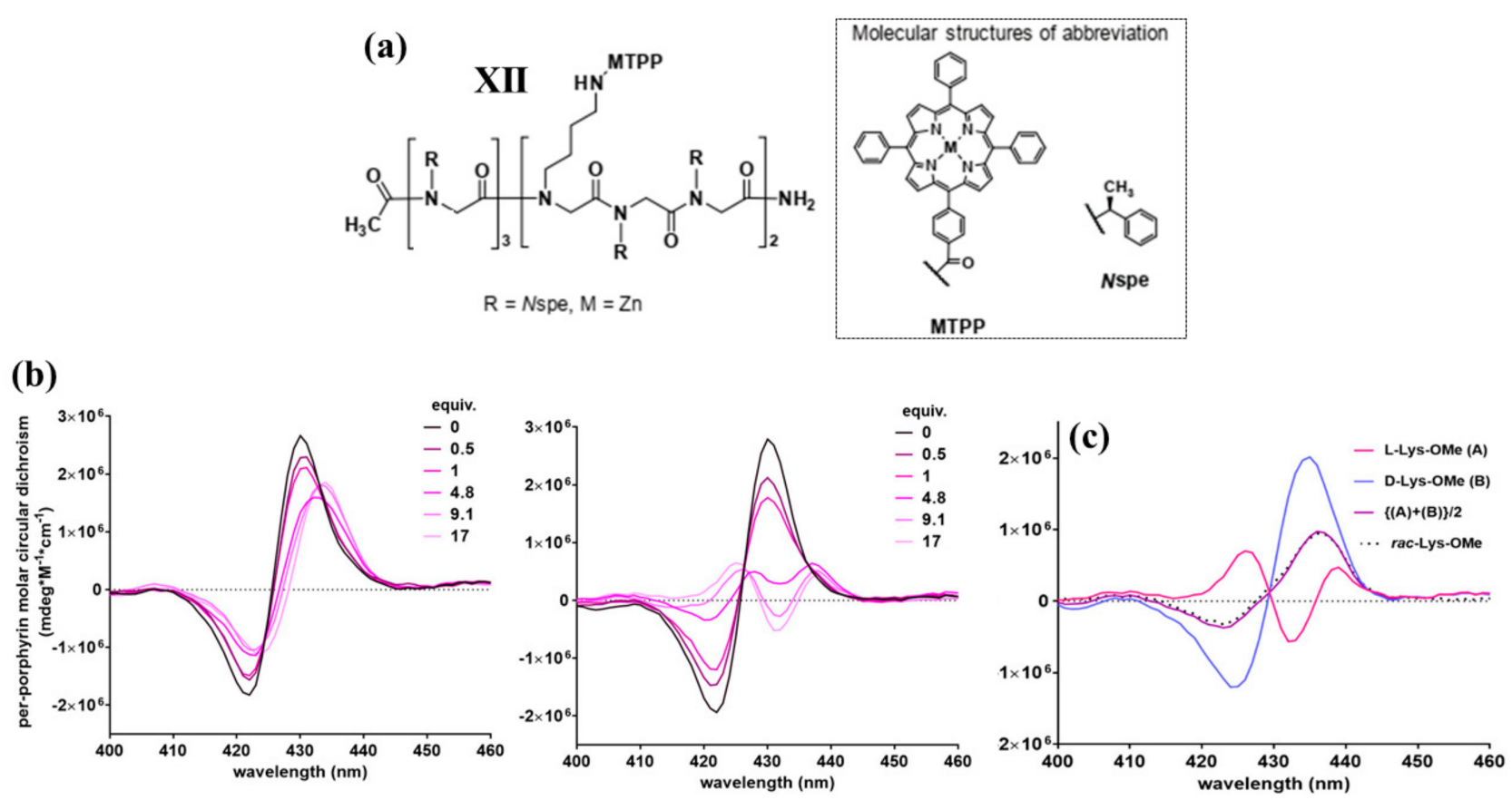

Figure 9. (a) Structure of the chiral metalloporphyrin tweezer bridged by a peptoid helix XII; (b) Titration CD spectra of chiral tweezer XII with an increasing amount of D- (on the left) and L-lysine methyl ester (on the right) in dichloromethane; (c) CD spectra of chiral tweezer XII with 17 equivalences of L-lysine methyl ester, D-lysine methyl ester, or racemic mixture of lysine methyl ester. Adapted from reference [67] under Creative Commons CC BY 4.0 license; published by MDPI AG 2018.
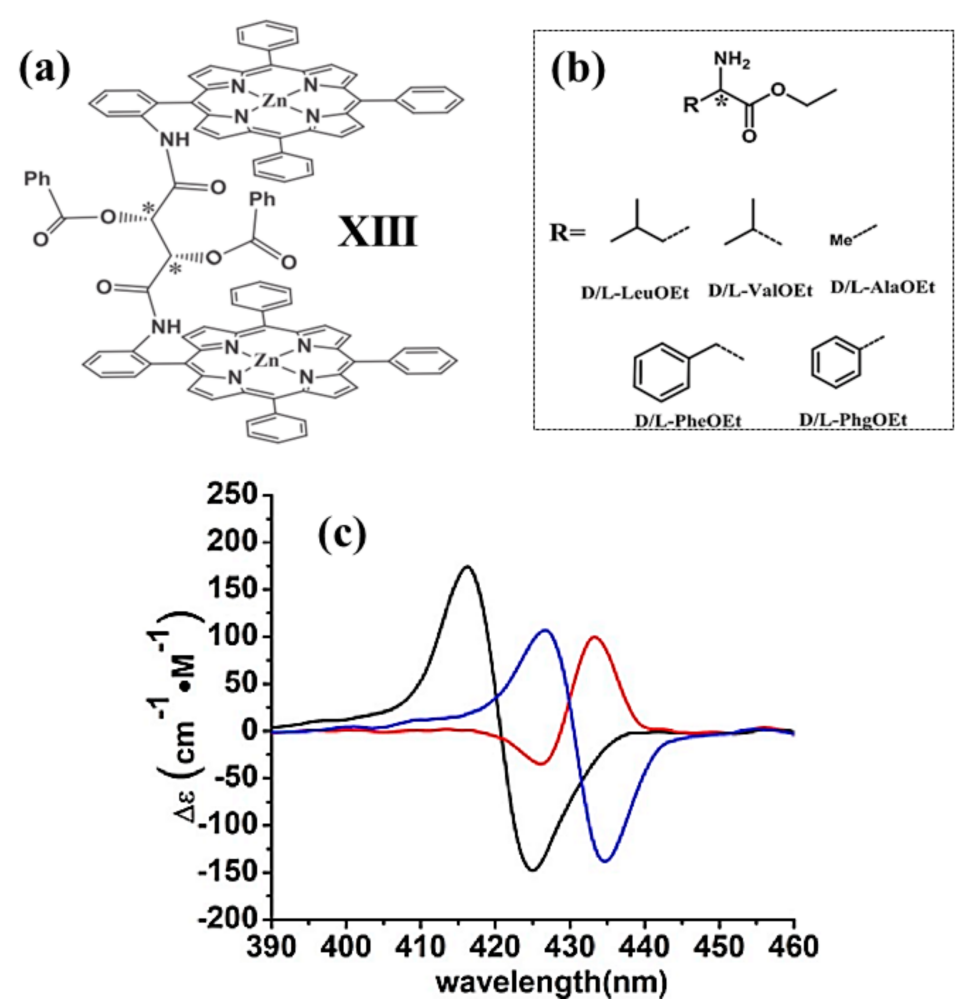

Figure 10. (a) Structure of the chiral zinc bisporphyrin XIII; (b) Structure of the chiral amino acid ester derivatives; (c) CD spectra in dichloromethane of the chiral zinc bisporphyrin XIII before (black curve) and after the addition of L-(blue curve) or D-phenylalanine ethyl ester (red curve). Adapted with permission from reference [68]; published by Elsevier 2020. 


\section{Chiral Recognition of Anionic and Neutral Guests}

\subsection{Monomeric Porphynoids}

A chiral Zn(II)-porphyrin derivate (Figure 11a, XIV) having N-phenylamide group was reported by Starnes and co-workers in 2012 [69]. Such system was investigated for chiral selectivity towards several anionic guests by using UV/Vis spectrophotometric titration in dichloromethane. In detail, for both enantiomers of $\mathrm{N}$-acetylalanine, $\mathrm{N}$-acetylphenylalanine, and $\mathrm{N}$-acetyltryptophan, chiral zinc-porphyrin exhibits a moderate selectivity. On the other hand, a better selectivity was observed to discriminate (S)- and (R)-mandelate isomers, evidencing a binding ratio (S)-/(R)- isomers around 2 . The ${ }^{1} \mathrm{H}$ NMR technique was performed to investigate the mechanism of complexation between chiral porphyrin XIV and mandelate isomers. ${ }^{1} \mathrm{H}$ NMR data suggest the well-known three-point interaction between chiral porphyrin and (S)-mandelate (Figure 11b), whereas for (R)-mandelate a less favorable complex is formed because of steric repulsion between the porphyrin ring and the phenyl group of mandelate (Figure 11b).
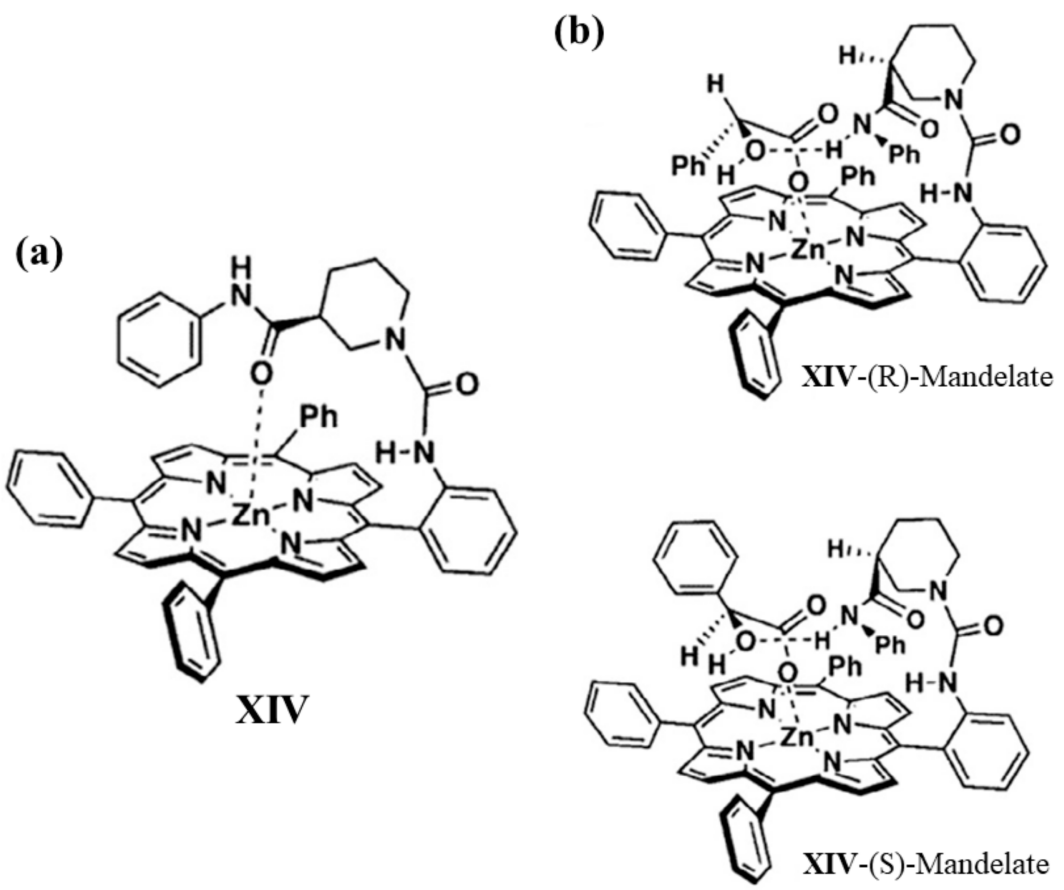

Figure 11. (a) Molecular structure of the chiral Zn(II)-porphyrin derivate XIV obtained by Starnes et al.; (b) Suggested complexes and relative interactions of XIV-(R)-mandelate (top) and XIV-(S)mandelate (bottom). Adapted with permission from reference [69]; published by American Chemical Society 2012.

In 2019, a hybrid material based on chiral Zn(II)-porphyrin derivates (Figure 12a, XV) and zinc oxide nanoparticles (ZnONP) was investigated by Stefanelli et al., for versatile sensing of vapors of enantiomer pairs of neutral guests, such as limonene, alpha-pinene, and butan-2-ol [70]. The hybrid material was simply obtained by dispersing uncoated $\mathrm{ZnO}$ nanoparticles in a toluene solution of porphyrin under an ultrasonic bath. CD spectroscopy was used to investigate the chiral organization in solution and in solid-state. In particular, the porphyrinoids are able to form self-aggregates both in solution and solid film as evidenced by CD spectra (Figure 12b). Interestingly, the dichroic bands in the porphyrin Soret region corroborate the fact that the solid-state film retains its original supramolecular chirality (Figure 12b). Conversely, the hybrid material (XV-ZnONP) reveals an additional dichroic band in the region of $\mathrm{ZnO}$ absorption (around $375 \mathrm{~nm}$ ), suggesting an effective chirality transfer via excitonic coupling from the tetrapyrrolic macrocycles to the $\mathrm{ZnO}$ surface. As a result, the presence of additional chiral sites in the $\mathrm{ZnO}$ surface may overcome 
all the other nonselective binding forces, thus providing a precise recognition towards a specific enantiomer.
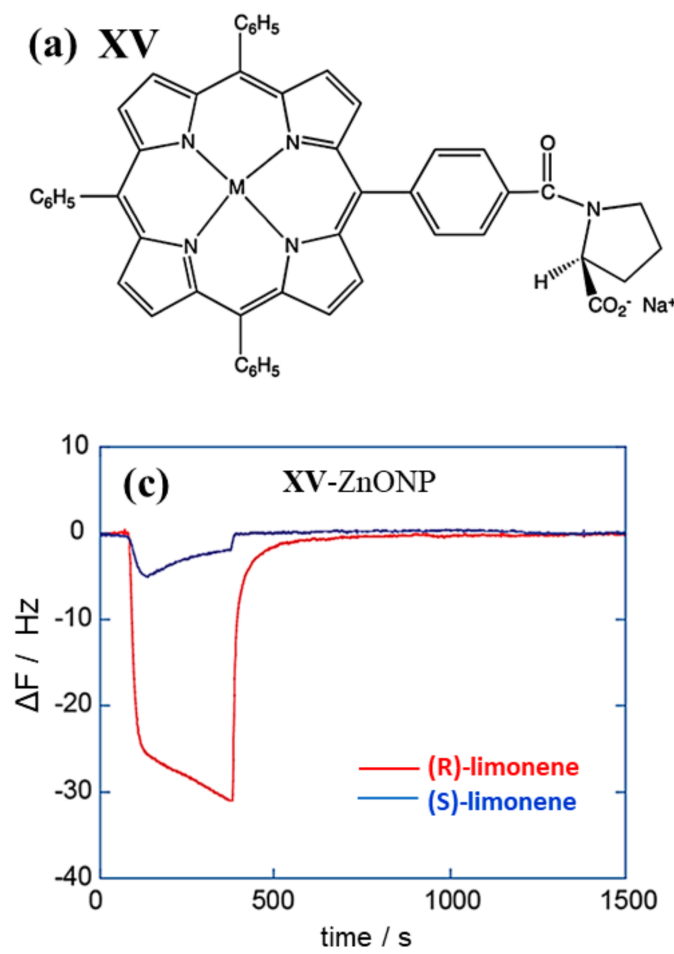

(b)

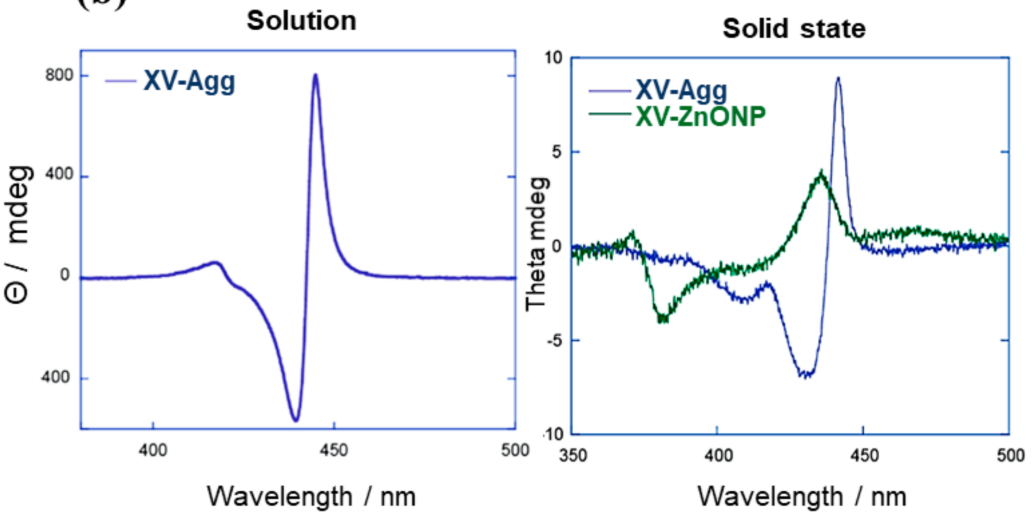

Figure 12. (a) Structure of the chiral Zn(II)-porphyrin XV (M = Zn); (b) CD-spectra of XV-aggregates in ethanol/water (on the left), CD-spectra respectively of $\mathbf{X V}$-aggregates (blue line) and $\mathbf{X V}$-ZnONP (green line) deposited on glass slide; (c) Dynamic of response of XV-ZnONP sensors to $160 \mathrm{ppm}$ of (R)- and (S)-limonene. Adapted with permission from reference [70]; published by American Chemical Society 2019.

Based on these considerations, the authors prepared a gas sensor suited for a quartz crystal microbalance (QCM). In fact, in a $20 \mathrm{MHz}$ QCM device, pristine AT-cut quartzes act as basic oscillators in the thickness-shear mode at a fundamental frequency of approximately $20 \mathrm{MHz}$ (i.e., AT-cut is one of the most commonly selected cutting angles in quartz crystal). As a consequence, QCMs are mass transducers, where the decrease (shift) in frequency $(\Delta \mathrm{F}, \mathrm{Hz})$ of a quartz crystal resonator is linearly correlated with an increase of mass loading/coated on it [71].

The functionalized sensor was achieved by the drop-casting onto AT-cut quartzes of a highly concentrated suspension of XV-ZnONP in toluene. Afterwards, the stereoselective properties of the sensor were tested with the exposure to vapors of enantiomer pairs $((\mathrm{R})$ - and (S)-limonene, (-)- $\alpha$ - and (+)- $\alpha$-pinene, (R)- and (S)-butan-2-ol) by measuring the frequency shift oscillation $(\triangle \mathrm{F}, \mathrm{Hz})$ in QCM. Particularly, the system was able to detect vapors of $\mathrm{R}$-enantiomer from limonene, in which the initial response to (R)-limonene is almost 5 times greater than that of (S)-limonene (Figure 12c).

\subsection{Bis-Porphyrin Systems and Porphyrin-Tweezers}

In 2005, a chiral bis-porphyrin (Figure 13a, XVI) with a C2 symmetry was reported by Ema et al. [72]. The bis-porphyrin XVI was explored as a receptor and chiral ${ }^{1} \mathrm{H}$ NMR shift agent for chiral diamines, aziridine, and isooxazoline in chloroform (Figure 13b).

The CD spectra of the bis-porphyrin enantiomer pairs (R, R)-XVI and (S, S)-XVI displayed a specular bisignate couplet in the porphyrin Soret region (Figure 13c), ascribable to the chiral exciton coupling between the two porphyrin chromophores. 

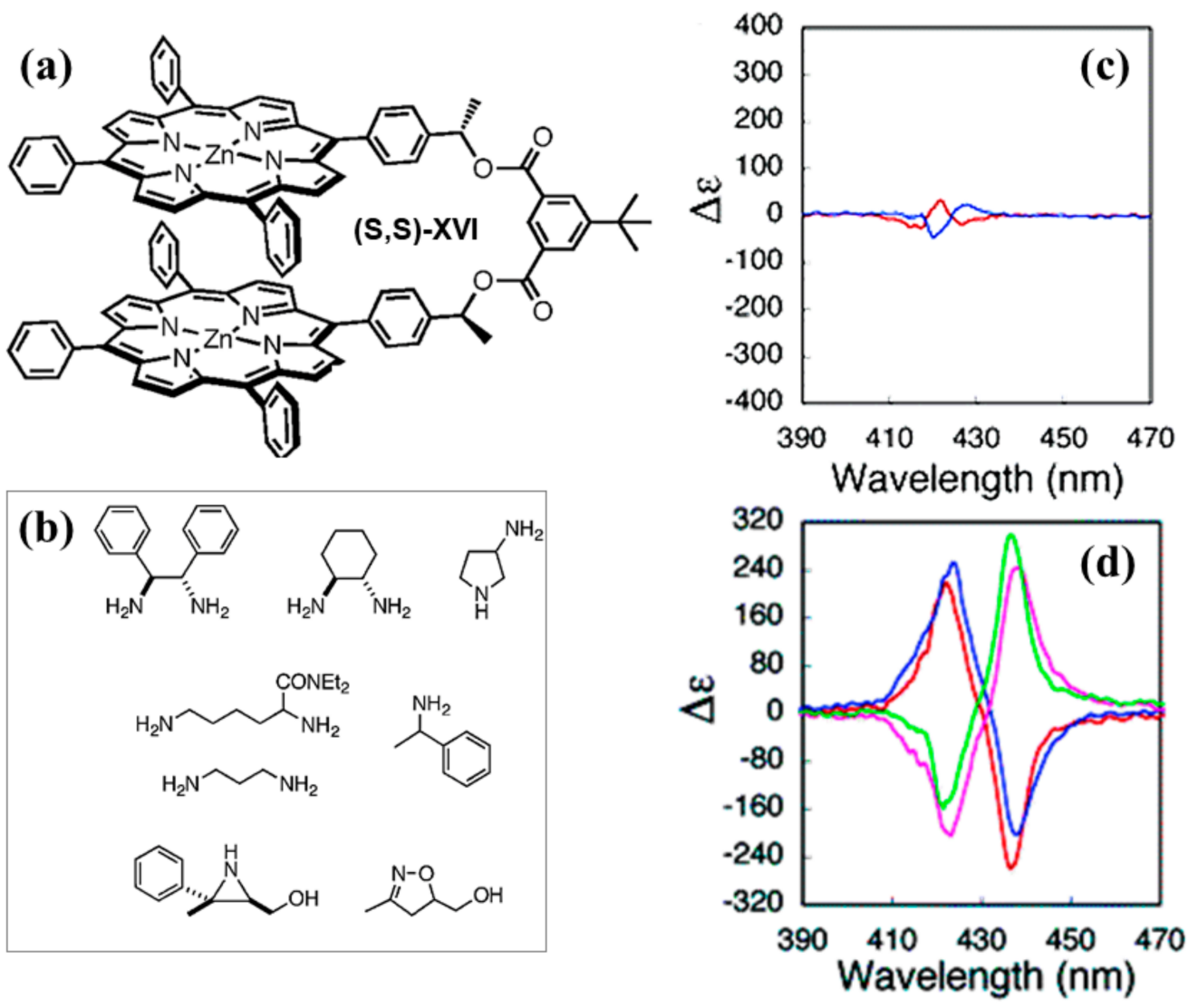

Figure 13. (a) Structure of the chiral bis-porphyrin XVI (reported the S, S-enantiomer); (b) Molecular structures of diamine, isooxazoline, and aziridines; (c) CD spectra of the bis-porphyrin enantiomer pairs (R, R-, red curve, S, S-, blue curve); (d) CD spectra of (R, R)-Zinc(II)-XVI in the presence of (i) (R)- (red curve) and (S)-cyclohexane diamine (pink curve), and those of (S, S)-Zinc(II)-XVI in the presence of (i) (R)- (blue curve) and (S)-cyclohexane diamine (green curve). Adapted with permission from reference [72]; published by American Chemical Society 2005.

Regarding the spectroscopic sensing, the binding of both chiral and achiral diamines tends to fix the conformation of the two porphyrin units, causing a significant amplification of the CD couplet. However, the effect of enhanced exciton coupling is strictly associated with the chirality and structure of the chiral diamine guests used. Interestingly, the binding with chiral diphenylethylene diamine leads to slight amplification of the CD signal as compared with uncomplexed porphyrin tweezer [72]. Conversely, the binding with chiral diamines having minor steric hindrance, such as cyclohexane diamine (CHDA), closes the two macrocycle chromophores, giving rise to an increased CD (Figure 13d). Noteworthy, in the case of diphenylethylene diamine and cyclohexane diamine, the sign of the CD couplets is governed by the initial chirality of guests used for the complexation (Figure 13d).

In the same year, a chiral Zn(II) bis-porphyrinoid (Figure 14a, XVII) was explored for enantiorecognition of chiral amines by Borovkov and coworkers [73]. The bis-porphyrinoid XVII was prepared as a racemic mixture and resolved by chiral HPLC. The resolved enantiomers displayed mirror-image $C D$ spectra, with bisignate couplets in the regions of chlorin B and Q transitions (Figure 14b) [74]. Significant changes of the corresponding CD signals were observed after the interaction of the $(R, R / R, R)$-XVII with the enantiomers of the chiral guest 2-aminobutane (Figure 14c). The CD spectra (Figure 14d) exhibited bathochromic shifts with lower intensity of the dichroic bands; finally, the interaction with the (S)-2-aminobutane inverted the sign of the $\mathrm{CD}$ bands in the $\mathrm{B}$ region. 


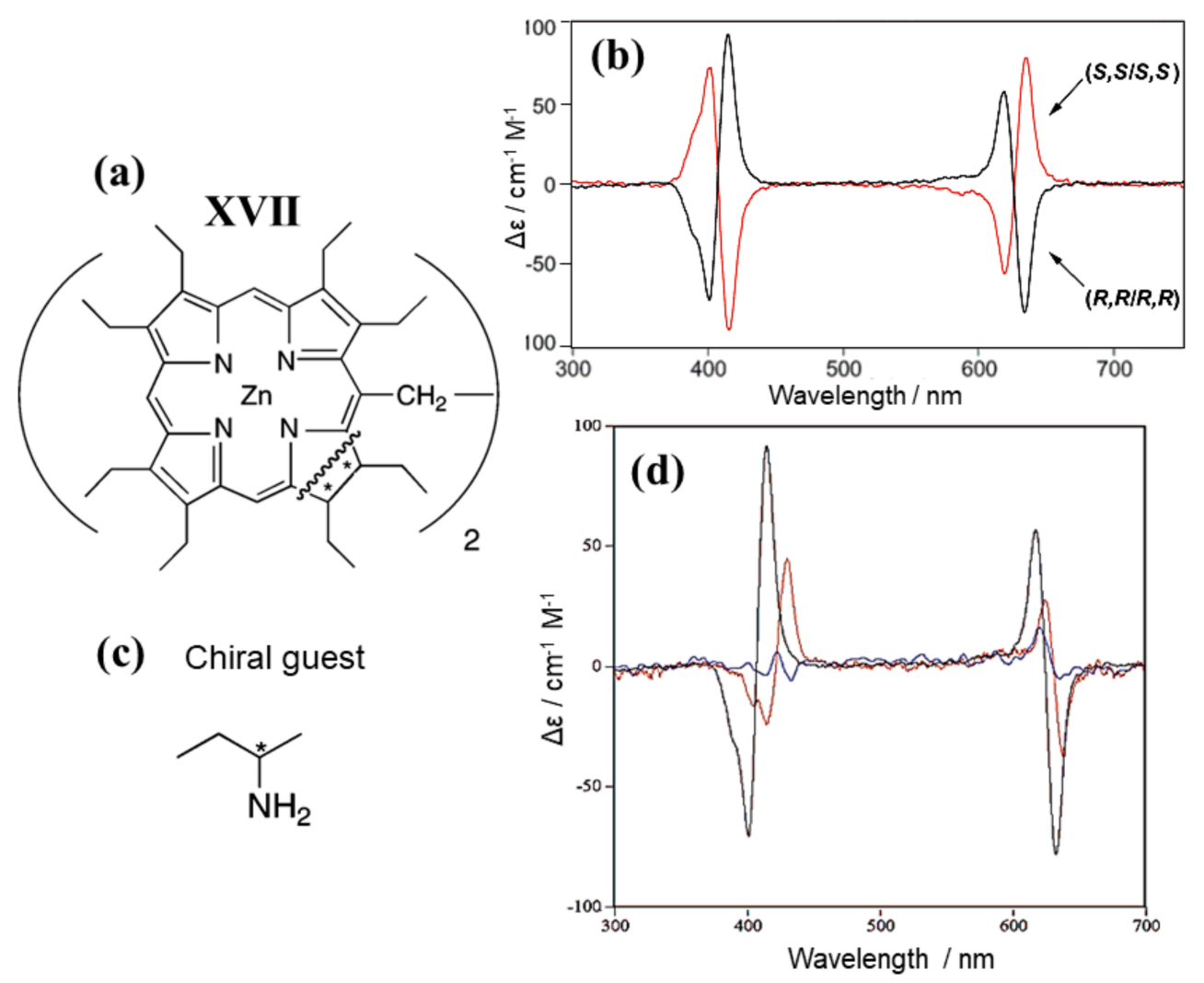

Figure 14. (a) Structure of the chiral Zn(II)-bis-porphyrinoid XVII; (b) CD spectra of enantiomers of chiral Zn(II)-XVII in dichloromethane; (c) Structure of the chiral 2-aminobutane; (d) CD spectra of (R, R/R, R)-Zinc(II)-XVII before (black line) and after the addition of (R)-2-aminobutane (red line) and (S)-2-aminobutane (blue line) in dichloromethane. Figure $14 \mathrm{a}, \mathrm{c}, \mathrm{d}$ adapted with permission from reference [73]; published by American Chemical Society 2005. Figure 14b adapted with permission from reference [74]; published by American Chemical Society 2005.

A double-decker porphyrin, (Figure 15a, XVIII) having one chiral cyclohexane-(1R, 2R)-dicarboxylic acid substituent per porphyrin ring, was investigated for enantioselective recognition of cyclohexane-1,2-dicarboxylic acid enantiomers by Takeuchi et al., in 2011 [75]. The CD spectra of the not-complexed XVIII disclosed a bisignate signal with a positive $C D$ band around $310 \mathrm{~nm}$ and negative bands around $400 \mathrm{~nm}$ (Figure 15b). By the addition of excess triethylamine, the positive $\mathrm{CD}$ band disappeared, and the negative bands decreased (Figure 15b) due to disruption of the intramolecular hydrogen bonding in the double-decker porphyrin. The CD titration experiments in tetrachloroethane-tetrahydrofuran 30:1 (v/v) mixed solvent (Figure 15c) - revealed a completely different dichroic coupling when the guest enantiomers were added: $(-/+)$ in case of $1 \mathrm{R}, 2 \mathrm{R}$ or $(+/-)$ in the presence of $1 \mathrm{~S}, 2 \mathrm{~S}$. In particular, the CD signal (at $310 \mathrm{~nm}$ ) of XVIII enhanced with increasing amounts of 1R, 2Renantiomer, whereas it diminished with the addition of 1S, 2S-enantiomer (Figure 15c,d). The stoichiometry of such host-guest complexes was evaluated by using the Hill equation for plots of the CD intensity at $310 \mathrm{~nm}$ (Figure 15d). Thus, from the slope of the linear Hill plots, Takeuchi et al., estimated a Hill coefficient $n_{H}$ equal to 2.0 for the XVIII $\cdot(1 \mathrm{R}, 2 \mathrm{R})$ complex and 2.8 for the XVIII $\cdot(1 \mathrm{~S}, 2 \mathrm{~S})$. Noteworthy, the $n_{H}$ coefficient provides important information about the stoichiometry of the complex [75]. As a result, the $n_{H}$ value for XVIII $\cdot(1 \mathrm{R}, 2 \mathrm{R})$ and XVIII $\cdot(1 \mathrm{~S}, 2 \mathrm{~S})$ complex suggested a 1:2, and 1:3 host-guest ratio, respectively. Nevertheless, these findings were also corroborated through the Job plot method by using the same CD intensity at $310 \mathrm{~nm}$. 


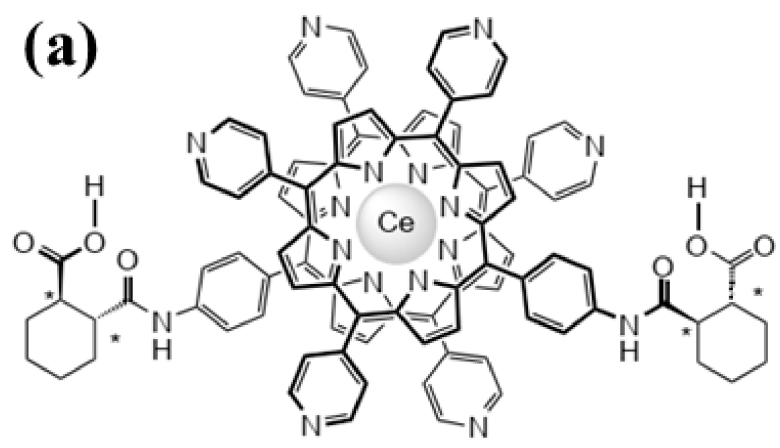

XVIII

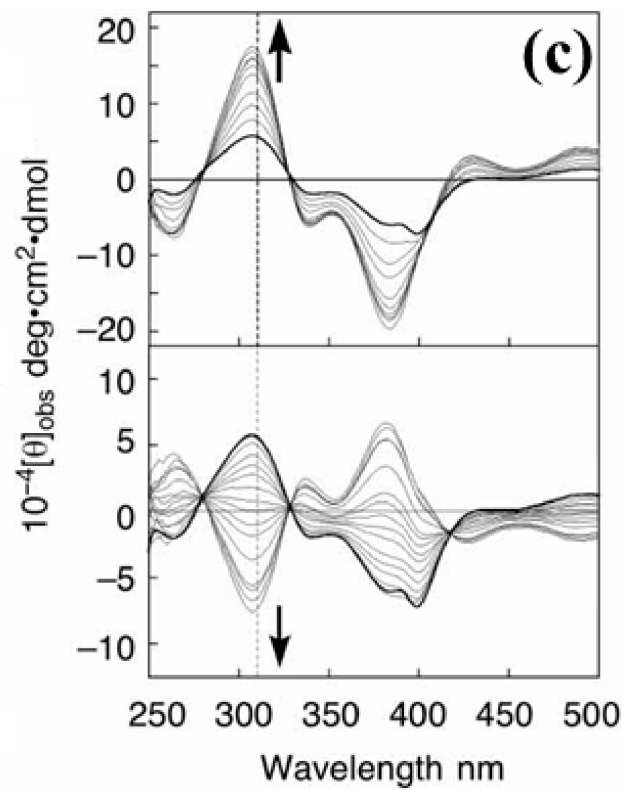

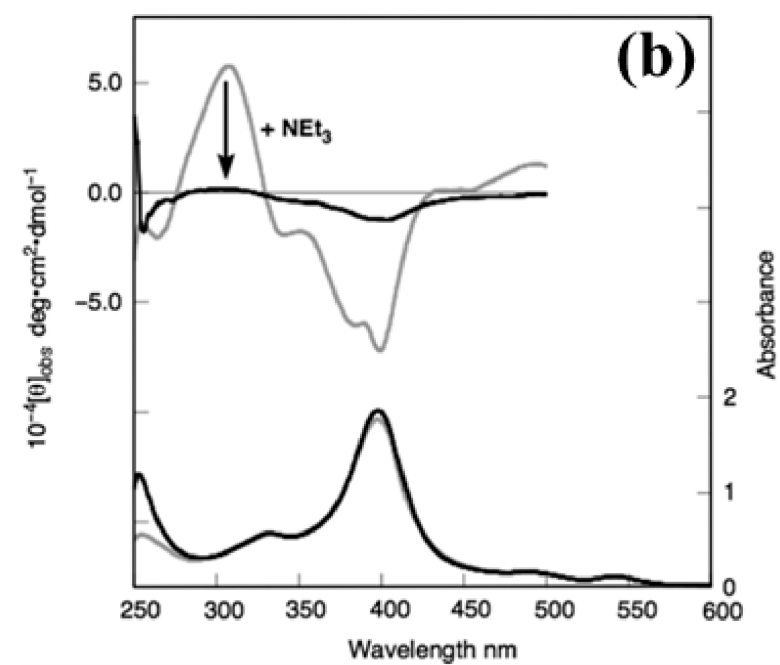

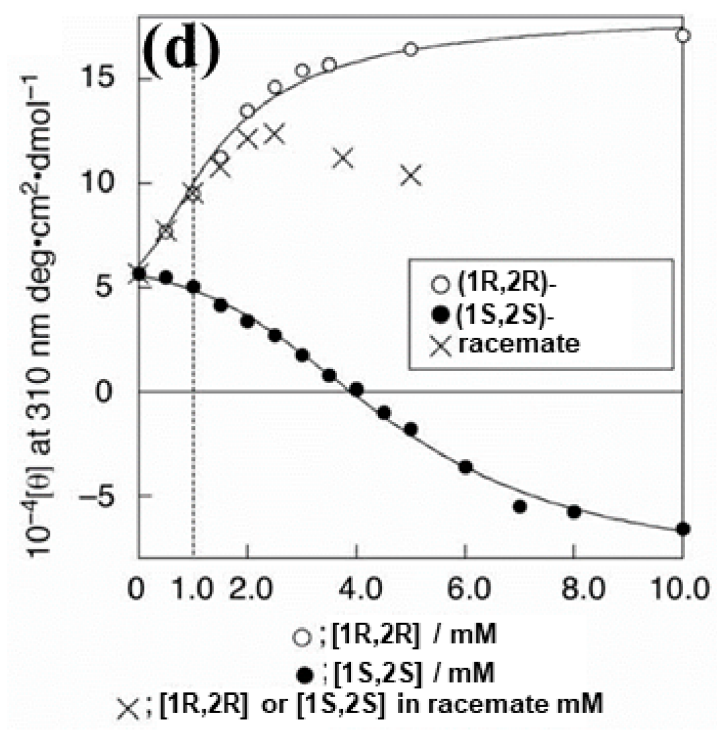

Figure 15. (a) Molecular structure of the chiral (R, R-) double-decker porphyrin XVIII. The stereogenic centres are indicated by an asterisk $\left({ }^{*}\right)$; (b) CD (top) and UV/Vis (bottom) spectra of porphyrin XVIII in tetrachloroethane-tetrahydrofuran 30:1 ( $v / v)$ mixed solvent without (grey line) and with triethylamine (black line); (c) Titration CD spectra of porphyrin XVIII with an increasing amount of cyclohexane-(1R, 2R)-dicarboxylic acid (top) and cyclohexane-(1S, 2S)-dicarboxylic acid (bottom). The bold lines refer to CD spectra of $1 \mathrm{R}$ in the absence of guest; (d) Plots of the CD intensity at $310 \mathrm{~nm}$ by adding an increasing amount of cyclohexane-(1R, 2R)-dicarboxylic acid (white dots), its chiral counterpart (black dots), and racemic mixture (cross), respectively. Adapted with permission from reference [75]; published by Taylor \& Francis 2011.

Moreover, the porphyrin exhibited high enantioselectivity towards $(1 \mathrm{R}, 2 \mathrm{R})$-cyclohexane1,2-dicarboxylic acid. This was demonstrated by using the racemic dicarboxylic acid guests throughout the titration experiments in place of related enantiomers (Figure 15d). Indeed, upon racemate's addition, the dichroic signal and intensity (at $310 \mathrm{~nm}$ ) follow a similar trend to that of pure cyclohexane-(1R, $2 \mathrm{R})$-dicarboxylic, becoming progressively more negative because of the competitive formation of XVIII $\cdot(1 \mathrm{~S}, 2 \mathrm{~S})$ complex.

A chiral porphyrin dimer (Figure 16a, XIX) having a macrocyclic cavity for intercalation of chiral and achiral aromatic guests was reported in the same period [76]. 

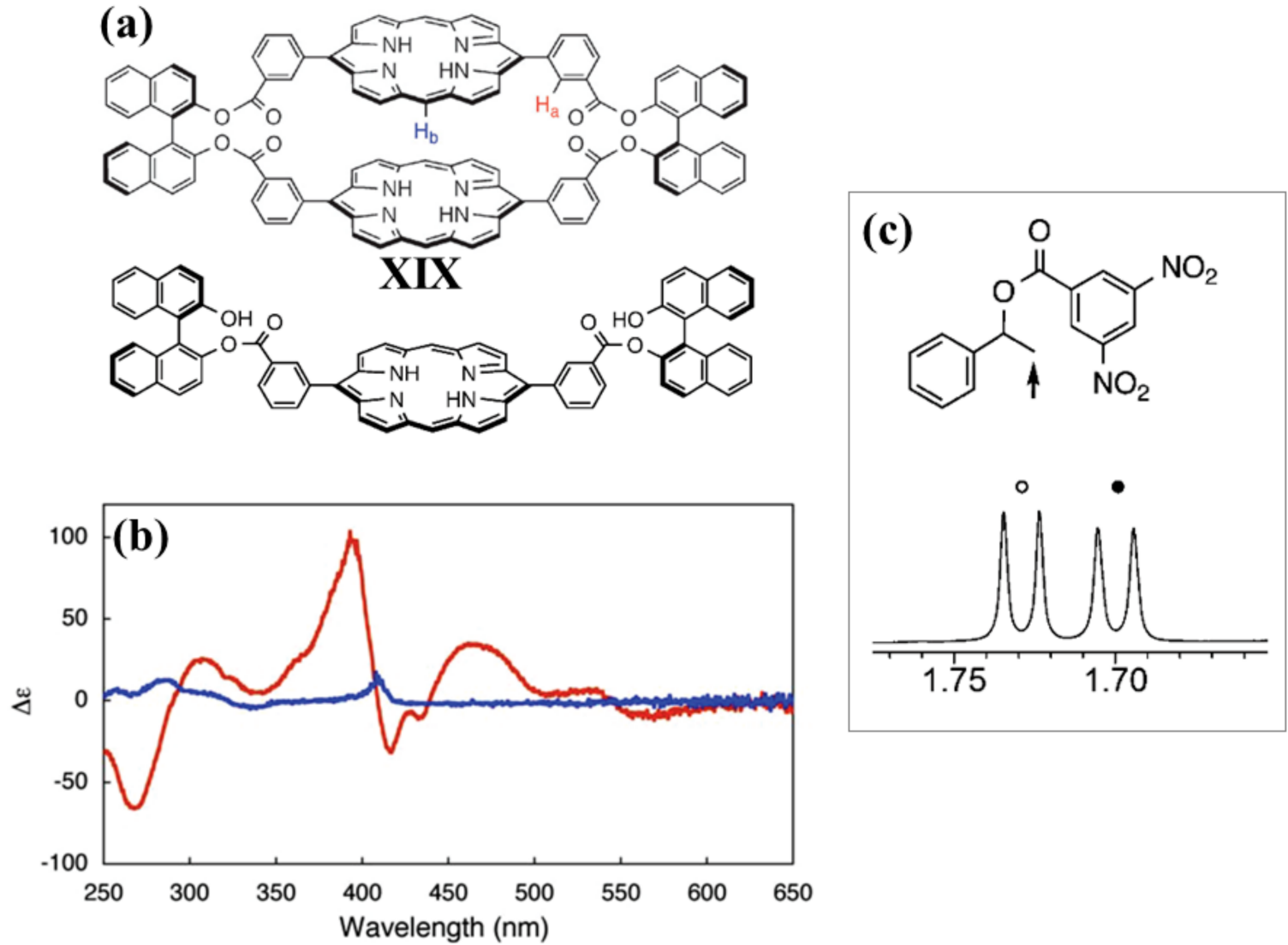

Figure 16. (a) Molecular structure of the chiral (R-) porphyrin dimer XIX (top) and the chiral monomer (bottom); (b) CD spectra of the chiral porphyrin dimer (red curve) and the corresponding chiral monomer (blue curve) in chloroform; (c) ${ }^{1} \mathrm{H}$ NMR of the racemic mixture of the ester of dinitrobenzoic acid in the presence of R-XIX in deuterated chloroform. In particular, the signals shown (bottom) refer to the protons indicated by the arrow. (R)- and (S)-enantiomer of the ester are labelled by filled and open circles, respectively. Adapted with permission from reference [76]; published by Royal Society of Chemistry 1996.

The chiral porphyrin monomers (Figure 16a, bottom) displayed a UV/Vis absorption centered around $410 \mathrm{~nm}$, with a corresponding limited optical activity in the same visible region (Figure 16b). However, when the dimer XIX was formed (Figure 16a, top), two spectroscopic phenomena occurred: (i) the Soret band was blue-shifted by $16 \mathrm{~nm}$ as compared with the corresponding monomer; (ii) the dichroic signal showed higher complexity, exhibiting as well a significant exciton-coupled CD (ECCD) (Figure 16b). According to the exciton model and ECCD theory [77-79], the porphyrin dimer XIX is made up of the two chiral monomers arranged in a face-to-face fashion.

Moreover, the porphyrin dimer exhibited a great affinity for electron-deficient aromatic guests, and it was shown to be very efficient as a chiral shift ${ }^{1} \mathrm{H}$ NMR agent for discriminating enantiomers of chiral molecules having dinitrophenyl moieties (Figure 16c).

Lu et al., reported in 2017 a chiral binaphthalene-bridged bisporphyrin with C2 symmetry (Figure 17a, XX) able to recognize chiral diamines in chloroform [80]. The CD spectra of the two enantiomer pairs point out a mirror image with a bisignate couplet in the porphyrin Soret region (Figure 17b). The UV/Vis investigations revealed that both enantiomers showed enantioselectivity towards chiral 1,2 diamines, with the highest ratio of 5.07 observed for $(1 \mathrm{R}, 2 \mathrm{R}) /(1 \mathrm{~S}, 2 \mathrm{~S})$-diaminecyclohexane. Nevertheless, different and almost specular dichroic spectra were obtained for R-enantiomer of the bis-porphyrin by the addition of (1S, 2S)-(Figure 17c) and (1R, 2R)-diaminecyclohexane (Figure 17d). 

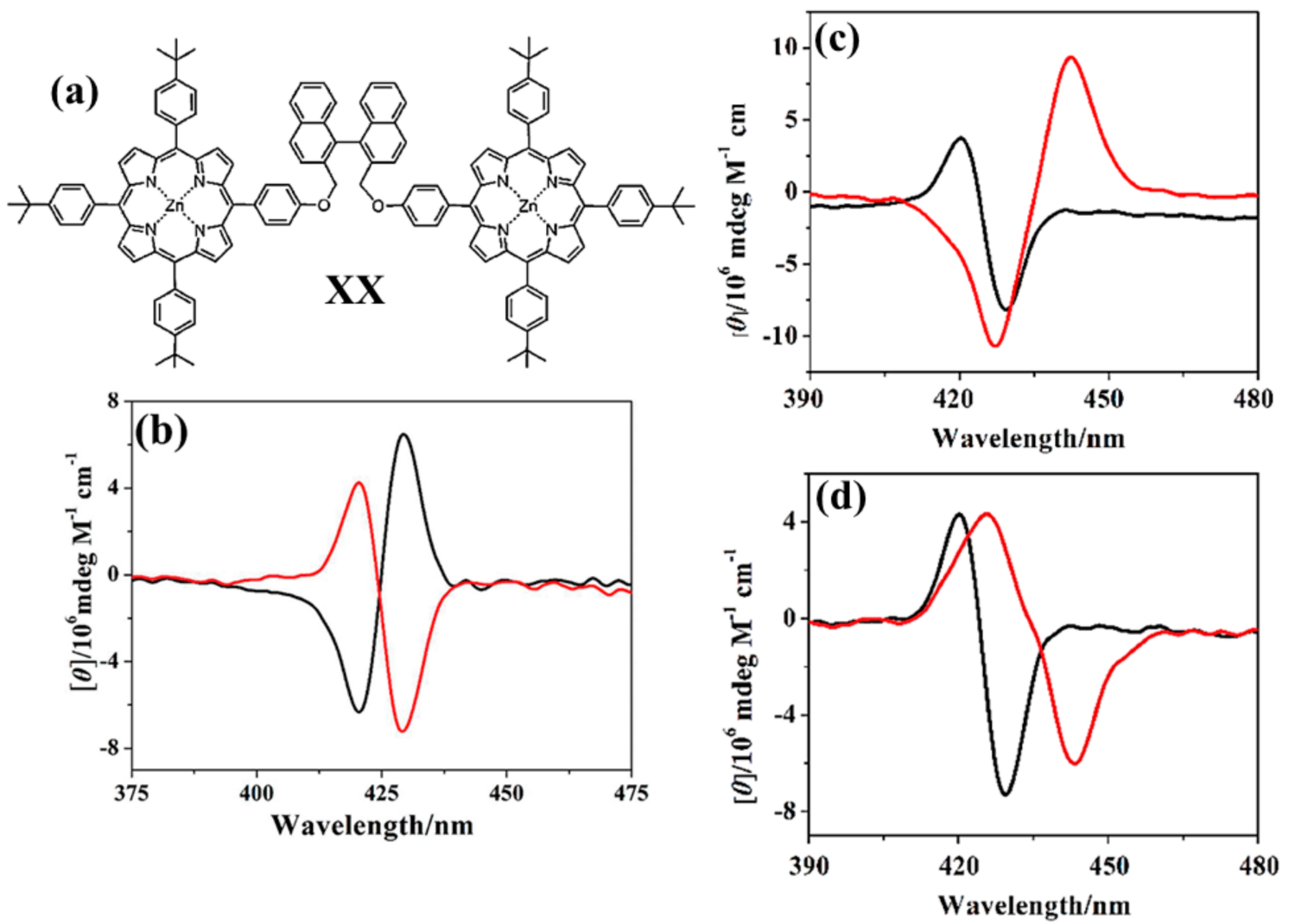

Figure 17. (a) Molecular structure of the chiral bis-porphyrin XX; (b) CD spectra of the two enantiomers of bis-porphyrin (R-, red curve, S-, black curve); (c) CD spectra of (R)-enantiomer of bis-porphyrin alone (black curve) and after (red curve) the addition of (1S, 2S)-diaminecyclohexane; (d) CD spectra of (R)-enantiomer of bis-porphyrin alone (black curve) and after (red curve) the addition of (1R, 2R)-diaminecyclohexane. Adapted with permission from reference [80]; published by American Chemical Society 2017.

Lately, a chiral diphenylethylene diamine bridged Zinc(II) bis-porphyrin tweezer (Figure 18a, XXI) was explored by Rath et al. [81] for chiral discrimination ability towards long and short chiral guests having one or two chiral centers. As short guests, both the enantiomers of cyclohexane diamine (CHDA) and diphenylethylene diamine (DPEA) were employed, whereas the investigated long guests are illustrated in Figure 18b.

The UV/Vis titration in chloroform (Figure 18c) highlighted that both enantiomers of the chiral tweezer XXI led to stoichiometric 1:1 sandwich complex, with all chiral guests illustrated in Figure 18b, evidencing a similar spectral behavior as well. Conversely, excess of smaller chiral diamines, such as $(1 \mathrm{~S}, 2 \mathrm{~S})$-cyclohexane diamine $\left(\mathrm{CHDA}_{(\mathrm{S}, \mathrm{S})}\right)$, yields dramatic changes in the UV/Vis spectral pattern ascribable to the formation of a 1:2 (R, R)- XXI • $\left(\mathrm{CHDA}_{(\mathrm{S}, \mathrm{S})}\right)$ complex. Noteworthy, other smaller diamines (i.e., DPEA) also behave similarly.

The circular dichroism spectra of the ( $R, R)$-XXI displays a bisignate couplet in the Soret band region (Figure 18d). However, after the addition of guests with one chiral center, the sign remained unchanged for both enantiomers, suggesting that the chirality is dictated by the host (Figure 18d). In contrast, the addition of (R, R)- or (S, S)-guests with two chiral centers provokes significant changes in the chirality of the bis-porphyrin. Indeed, the $C D$ couplet sign is inverted in the presence of (S, S)-guests, implying that the chirality, in this case, is dictated by the guest (Figure 18e). Nonetheless, the dichroic spectral variations are quite different in the presence of smaller chiral guests such as CHDA and DPEA. The CD changes follow the stepwise formations of 1:1 sandwich and 1:2 host-guest complexes. However, the size mismatch between the host and smaller chiral guest results in a weaker interaction and, therefore, as compared with longer guests, a lower CD amplitude is expected. 

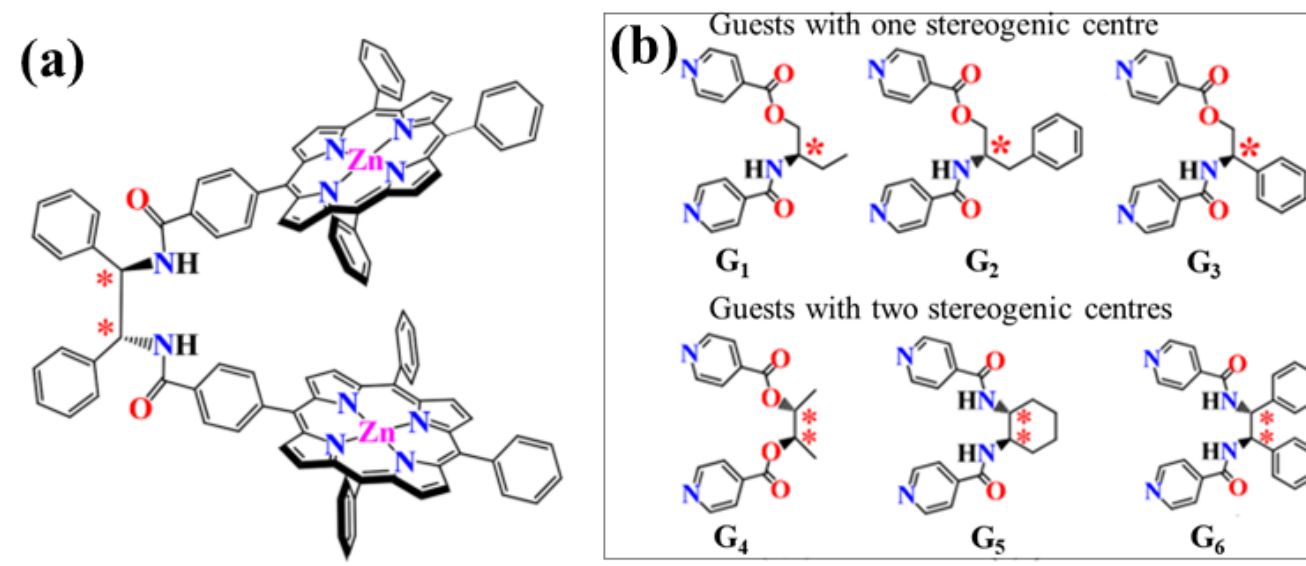

Guests with two stereogenic centres

\section{(R,R)-XXI}
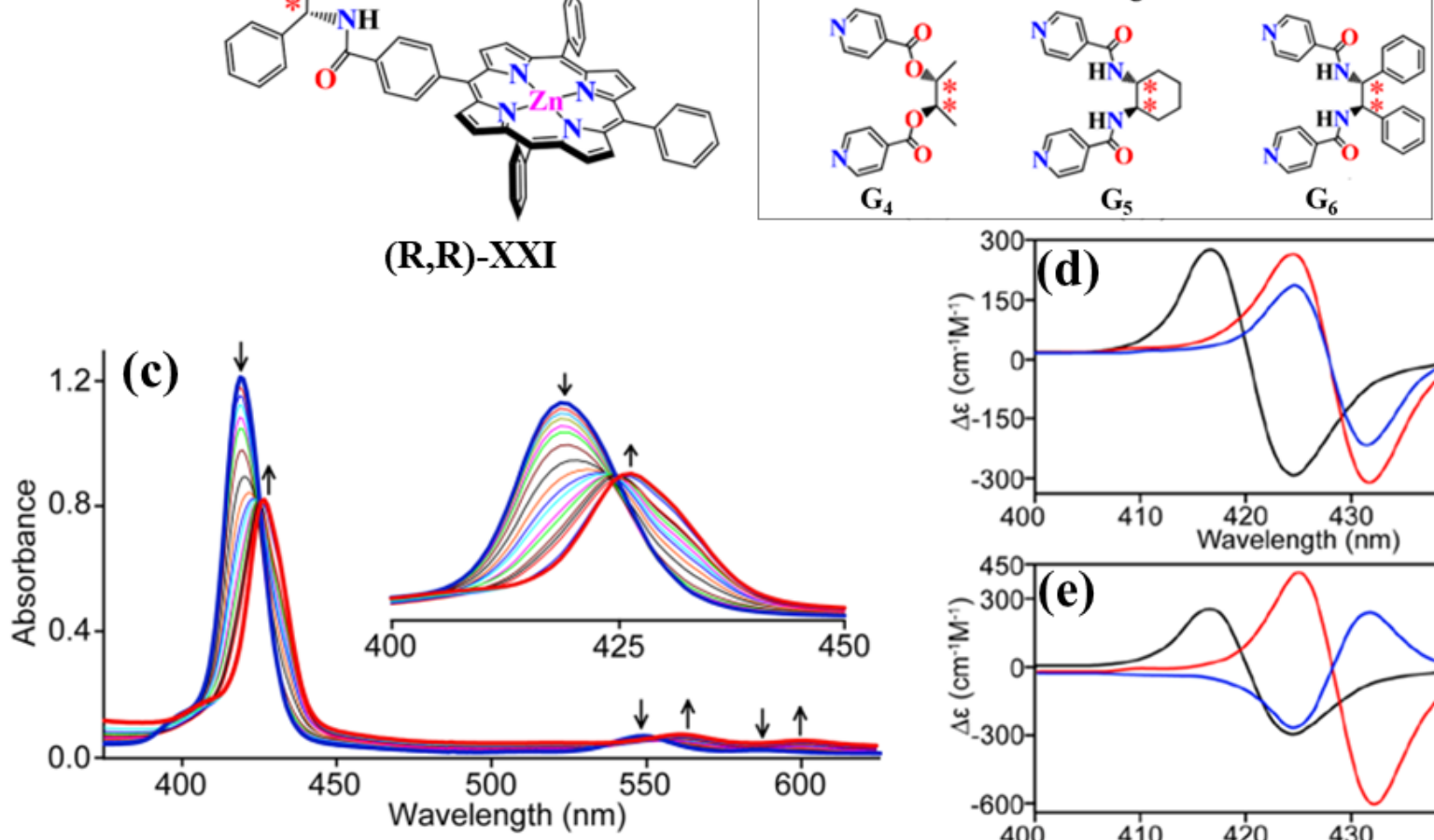

$\mathbf{G}_{4}$
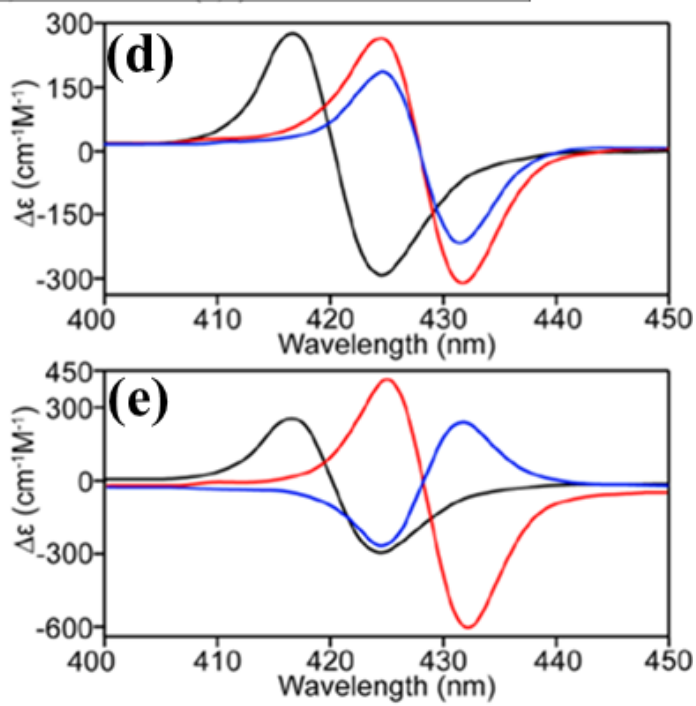

Figure 18. (a) Molecular structure of the (R, R)-diphenylethylenediamine bridged Zinc(II) bis-porphyrin tweezer XXI; (b) Structure of the long chiral diamines used in the research. The stereogenic centres are indicated by an asterisk $\left({ }^{*}\right)$;

(c) UV/Vis titration of (R, R)-XXI with an increasing amount of (R, R)- $\mathrm{G}_{5}$ in chloroform; (d) Circular dichroism spectra of (R, R)-XXI before (black line) and after the addition of (R)- $\mathrm{G}_{\mathbf{1}}$ (red line) and of (S)-G (blue line) in chloroform; (e) Circular dichroism spectra of (R, R)-XXI before (black line) and after the addition of (R, R)- $G_{5}$ (red line) and of (S, S)- $G_{5}$ (blue line) in chloroform. Adapted with permission from reference [81]; published by American Chemical Society 2020.

Moreover, the computational analysis of the $\mathrm{CD}$ titration reported that the (R, R)-XXI exhibits large enantioselectivity for long chiral diamines (Figure 18b) reaching, for instance, the highest value for $(\mathrm{R}, \mathrm{R})-\mathrm{G}_{5} /(\mathrm{S}, \mathrm{S})-\mathrm{G}_{5}$ ratio.

Most recently, Elemans, Nolte and coworkers reported an unusual chiral macrocyclic porphyrin (Figure 19a, XXII) with a C2 symmetry for the kinetic enantiorecognition of chiral viologen molecules, illustrated in Figure 19b [82]. The CD spectra of the enantiomer pairs (R, R, R, R)- and (S, S, S, S)-XXII displayed mirror-image signals with bands centered at $\sim 415 \mathrm{~nm}$ (Figure 19c). Time-resolved fluorescence studies indicated that the porphyrin enantiomers have high kinetic stereoselectivity towards viologens with chiral moieties located in the final part of the molecule (M2, M4), whereas no kinetic stereoselectivity was shown for viologens with chiral moieties more distant from the chain termini (M1, M3) (Figure 19d), indicating that the location of the chiral moiety in the final part of the guest is crucial for enantiorecognition by the host XXII. 
(a)

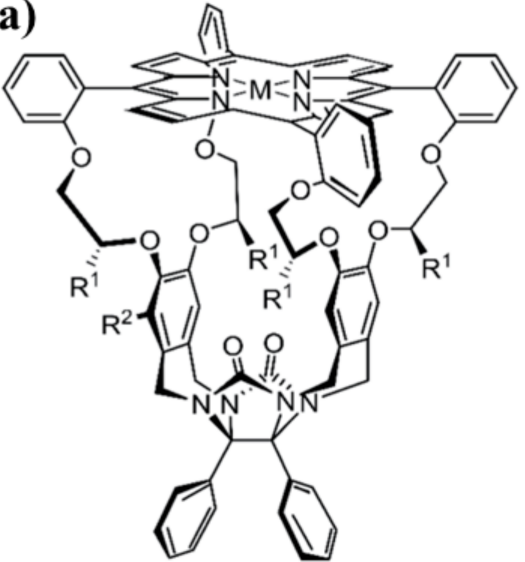

$(\mathrm{R}, \mathrm{R}, \mathrm{R}, \mathrm{R})-\mathbf{X X I I}\left(\mathrm{M}=2 \mathrm{H}, \mathrm{R}^{1}=\mathrm{Me}, \mathrm{R}^{2}=\mathrm{H}\right)$

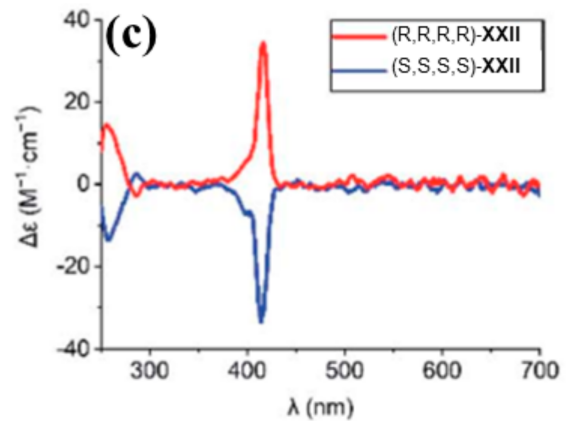

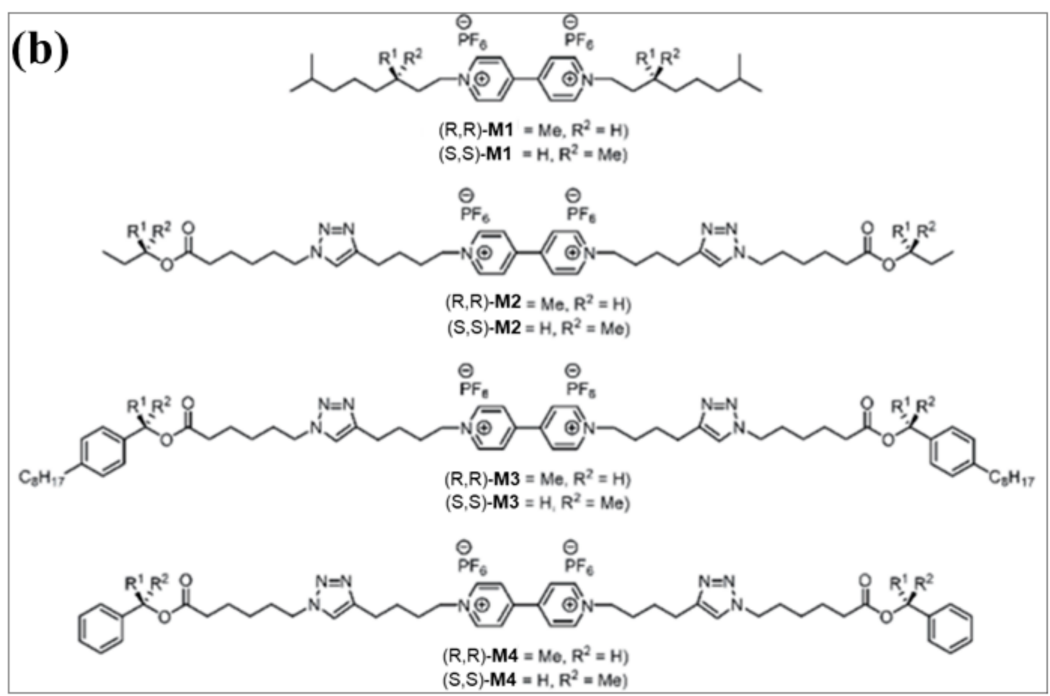

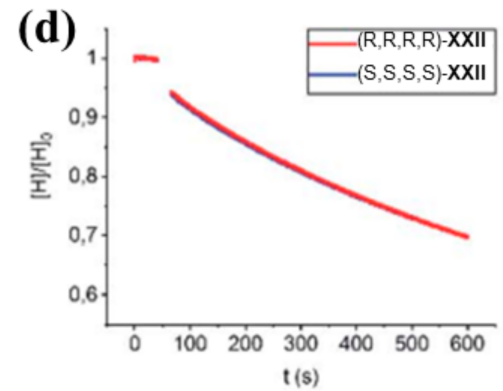

Figure 19. (a) Molecular structure of the chiral macrocyclic porphyrin XXII; (b) Chemical structures of viologen molecules. (c) CD spectra of enantiomers ( R, R, R, R)- and (S, S, S, S)-XXII in chloroform-acetonitrile 1:1 (v/v) mixed solvent; (d) Normalized fluorescence intensity of enantiomers (R, R, R, R)- and (S, S, S, S)-XXII as a function of time after the addition of 1 equivalent of ( $R, R)-M 3$ (on the left) and ( $R, R)-M 4$ (on the right). Adapted from reference [82] under Creative Commons Attribution 3.0 Unported License; published by Royal Society of Chemistry 2021.

\section{Conclusions}

Chiral recognition is one of the most important issues in the natural world, and it is widespread in biological systems. Indeed, being of particular interest to researchers, such a phenomenon has been extensively studied over the past few decades. The basis of the chiral recognition mechanism is the formation of diastereoisomeric complexes between the enantiomers and a pre-organized chiral selector with a minimum of three-points interaction for the enantiomeric recognition [83-85]. Porphyrinoids and bis-porphyrinoids, owing to their versatile synthesis capacity, can be constructed appropriately as hosts for molecular recognition of a specific guest. In this review, several chiral guests were reported, especially amino acids and their derivates, for their biological relevance and analogous molecules, such as amines and diamines. However, most of the studies perform the chiral recognition phenomena in organic solvents (e.g., dichloromethane or chloroform), which do not hinder the supramolecular interactions between the hosts and guest molecules. Thus, the concepts gathered in this review may encourage the design of chiral porphyrinoid hosts able to enantio-recognize chiral molecules in water so as to mimic the biological aqueous environment.

Author Contributions: Conceptualization, A.D.; writing—original draft preparation, G.T. and M.G.; data curation, G.T. and M.G.; writing-review and editing, M.G., R.P. and A.D.; visualization, M.G. and A.D.; supervision, A.D.; funding acquisition, A.D. All authors have read and agreed to the published version of the manuscript. 
Funding: This research was funded by Ministero dell'Istruzione, dell'Università e della Ricerca (MIUR) PRIN Prot. 2017YJMPZN-005; Programma ricerca di ateneo UNICT 2020-2022 linea 2; Progetto “sAMpEI" Misura 2.51 PO FEAMP 2014-2020-CUP: G67B18000260009; Programma ricerca di ateneo UNICT 2016-18 linea 1 and 2.

Institutional Review Board Statement: Not applicable.

Informed Consent Statement: Not applicable.

Data Availability Statement: Data sharing is not applicable to this article.

Conflicts of Interest: The authors declare no conflict of interest. The funders had no role in the design of the study; in the collection, analyses, or interpretation of data; in the writing of the manuscript; or in the decision to publish the results.

\section{References}

1. Baron, R.; McCammon, J.A. Molecular recognition and ligand association. Annu. Rev. Phys. Chem. 2013, 64, 151-175. [CrossRef]

2. Persch, E.; Dumele, O.; Diederich, F. Molecular recognition in chemical and biological systems. Angew. Chem. Int. Ed. 2015, 54, 3290-3327. [CrossRef]

3. Arnaboldi, S.; Benincori, T.; Penoni, A.; Vaghi, L.; Cirilli, R.; Abbate, S.; Longhi, G.; Mazzeo, G.; Grecchi, S.; Panigati, M.; et al. Highly enantioselective "inherently chiral" electroactive materials based on a 2,2'-biindole atropisomeric scaffold. Chem. Sci. 2019, 10, 2708-2717. [CrossRef]

4. Ousaka, N.; Yamamoto, S.; Iida, H.; Iwata, T.; Ito, S.; Hijikata, Y.; Irle, S.; Yashima, E. Water-mediated deracemization of a bisporphyrin helicate assisted by diastereoselective encapsulation of chiral guests. Nat. Commun. 2019, 10, 1-11. [CrossRef]

5. Baars, M.W.P.L.; Meijer, E.W. Host-Guest Chemistry of Dendritic Molecules. In Dendrimers II. Topics in Current Chemistry; Vögtle, F., Ed.; Springer: Berlin/Heidelberg, Germany, 2000; Volume 210, pp. 131-182.

6. Gattuso, G.; Notti, A.; Pappalardo, S.; Parisi, M.F.; Pisagatti, I. Recognition in water of bioactive substrates by a sulphonato p-tert-butylcalix[5]arene. Supramol. Chem. 2014, 26, 597-600. [CrossRef]

7. Rekharsky, M.V.; Yamamura, H.; Inoue, C.; Kawai, M.; Osaka, I.; Arakawa, R.; Shiba, K.; Sato, A.; Young, H.K.; Selvapalam, N.; et al. Chiral recognition in cucurbituril cavities. J. Am. Chem. Soc. 2006, 128, 14871-14880. [CrossRef]

8. Corradini, R.; Sforza, S.; Tedeschi, T.; Marchelli, R. Chirality as a tool in nucleic acid recognition: Principles and relevance in biotechnology and in medicinal chemistry. Chirality 2007, 19, 269-294. [CrossRef]

9. Zhang, L.; Jin, Q.; Liu, M. Enantioselective Recognition by Chiral Supramolecular Gels. Chem. Asian J. 2016, 11, 2642-2649. [CrossRef]

10. Farinone, M.; Urbańska, K.; Pawlicki, M. BODIPY- and Porphyrin-Based Sensors for Recognition of Amino Acids and Their Derivatives. Molecules 2020, 25, 4523. [CrossRef]

11. Gaeta, M.; Rodolico, E.; Fragalà, M.E.; Pappalardo, A.; Pisagatti, I.; Gattuso, G.; Notti, A.; Parisi, M.F.; Purrello, R.; D’Urso, A. Self-assembly of discrete porphyrin/calix[4]tube complexes promoted by potassium ion encapsulation. Molecules 2021, 26, 704. [CrossRef] [PubMed]

12. Ceccacci, F.; Mancini, G.; Sferrazza, A.; Villani, C. pH variation as the switch for chiral recognition in a biomembrane model. J. Am. Chem. Soc. 2005, 127, 13762-13763. [CrossRef]

13. Yashima, E.; Maeda, K.; Nishimura, T. Detection and Amplification of Chirality by Helical Polymers. Chem. Eur. J. 2004, 10, 42-51. [CrossRef]

14. Guo, D.S.; Wang, K.; Liu, Y. Selective binding behaviors of p-sulfonatocalixarenes in aqueous solution. J. Incl. Phenom. Macrocycl. Chem. 2008, 62, 1-21. [CrossRef]

15. Randazzo, R.; Gaeta, M.; Gangemi, C.M.A.; Fragalà, M.E.; Purrello, R.; D'Urso, A. Chiral recognition of L- and D-amino acid by porphyrin supramolecular aggregates. Molecules 2019, 24, 84. [CrossRef]

16. Lintuluoto, J.M.; Borovkov, V.V.; Inoue, Y. Direct determination of absolute configuration of monoalcohols by bis (magnesium porphyrin). J. Am. Chem. Soc. 2002, 124, 13676-13677. [CrossRef]

17. De Luca, G.; Romeo, A.; Scolaro, L.M.; Pasternack, R.F. Conformations of a model protein revealed by an aggregating CuII porphyrin: Sensing the difference. Chem. Commun. 2010, 46, 389-391. [CrossRef]

18. Yang, L.; Zhou, Y.; Zhu, M.; Zhao, L.; Wei, L.; Bian, Y. Stereochemistry and solid-state structure of an intrinsically chiral meso-patterned porphyrin: Case study by NMR and single-crystal X-ray diffraction analysis. J. Org. Chem. 2013, 78, 9949-9955. [CrossRef]

19. Gaeta, M.; Randazzo, R.; Cristaldi, D.A.; D’Urso, A.; Purrello, R.; Fragalà, M.E. ZnTPPS demetalation: Role of polyelectrolytes on aggregation after protonation in acid. J. Porphyr. Phthalocyanines 2017, 21, 426-430. [CrossRef]

20. Romeo, A.; Castriciano, M.A.; Zagami, R.; Pollicino, G.; Monsù Scolaro, L.; Pasternack, R.F. Effect of zinc cations on the kinetics of supramolecular assembly and the chirality of porphyrin J-aggregates. Chem. Sci. 2017, 8, 961-967. [CrossRef]

21. Monti, D.; Nardis, S.; Stefanelli, M.; Paolesse, R.; Di Natale, C.; D'Amico, A. Porphyrin-based nanostructures for sensing applications. J. Sens. 2009, 2009. [CrossRef] 
22. Paolesse, R.; Nardis, S.; Monti, D.; Stefanelli, M.; Di Natale, C. Porphyrinoids for Chemical Sensor Applications. Chem. Rev. 2017, 117, 2517-2583. [CrossRef]

23. Panda, M.K.; Ladomenou, K.; Coutsolelos, A.G. Porphyrins in bio-inspired transformations: Light-harvesting to solar cell. Coord. Chem. Rev. 2012, 256, 2601-2627. [CrossRef]

24. Jurow, M.; Schuckman, A.E.; Batteas, J.D.; Drain, C.M. Porphyrins as molecular electronic components of functional devices Coord. Chem. Rev. 2010, 254, 2297-2310. [CrossRef] [PubMed]

25. Kou, J.; Dou, D.; Yang, L. Porphyrin photosensitizers in photodynamic therapy and its applications. Oncotarget 2017, 8, 8159181603. [CrossRef]

26. Kano, K. Porphyrin-cyclodextrin supramolecular complexes as myoglobin model in water. Colloid Polym. Sci. 2008, 286, 79-84 [CrossRef]

27. Silva, E.F.F.; Serpa, C.; Dąbrowski, J.M.; Monteiro, C.J.P.; Formosinho, S.J.; Stochel, G.; Urbanska, K.; Simões, S.; Pereira, M.M.; Arnaut, L.G. Mechanisms of singlet-oxygen and superoxide-ion generation by porphyrins and bacteriochlorins and their implications in photodynamic therapy. Chem. Eur. J. 2010, 16, 9273-9286. [CrossRef]

28. Mateos-Timoneda, M.A.; Crego-Calama, M.; Reinhoudt, D.N. Supramolecular chirality of self-assembled systems in solution. Chem. Soc. Rev. 2004, 33, 363-372. [CrossRef]

29. Huang, X.; Fujioka, N.; Pescitelli, G.; Koehn, F.E.; Williamson, R.T.; Nakanishi, K.; Berova, N. Absolute configurational assignments of secondary amines by CD-sensitive dimeric zinc porphyrin host. J. Am. Chem. Soc. 2002, 124, 10320-10335. [CrossRef] [PubMed]

30. Saha, B.; Ikbal, S.A.; Petrovic, A.G.; Berova, N.; Rath, S.P. Complexation of Chiral Zinc-Porphyrin Tweezer with Achiral Diamines: Induction and Two-Step Inversion of Interporphyrin Helicity Monitored by ECD. Inorg. Chem. 2017, 56, 3849-3860. [CrossRef]

31. Kurtán, T.; Nesnas, N.; Li, Y.Q.; Huang, X.; Nakanishi, K.; Berova, N. Chiral recognition by CD-sensitive dimeric zinc porphyrin host. 1. Chiroptical protocol for absolute configurational assignments of monoalcohols and primary monoamines. J. Am. Chem. Soc. 2001, 123, 5962-5973. [CrossRef]

32. Proni, G.; Pescitelli, G.; Huang, X.; Quraishi, N.Q.; Nakanishi, K.; Berova, N. Configurational assignment of $\alpha$-chiral carboxylic acids by complexation to dimeric Zn-porphyrin: Host-guest structure, chiral recognition and circular dichroism. Chem. Commun. 2002, 2, 1590-1591. [CrossRef]

33. Ishii, H.; Chen, Y.; Miller, R.A.; Karady, S.; Nakanishi, K.; Berova, N. Chiral recognition of cyclic $\alpha$-hydroxyketones by CD-sensitive zinc tetraphenylporphyrin tweezer. Chirality 2005, 17, 305-315. [CrossRef] [PubMed]

34. Angelini, N.; Micali, N.; Mineo, P.; Scamporrino, E.; Villari, V.; Vitalini, D. Uncharged water-soluble Co(II)—Porphyrin: A receptor for aromatic $\alpha$-amino acids. J. Phys. Chem. B 2005, 109, 18645-18651. [CrossRef]

35. Borovkov, V.V.; Lintuluoto, J.M.; Inoue, Y. Supramolecular chirogenesis in zinc porphyrins: Mechanism, role of guest structure, and application for the absolute configuration determination. J. Am. Chem. Soc. 2001, 123, 2979-2989. [CrossRef]

36. Gholami, H.; Anyika, M.; Zhang, J.; Vasileiou, C.; Borhan, B. Host-Guest Assembly of a Molecular Reporter with Chiral Cyanohydrins for Assignment of Absolute Stereochemistry. Chem. Eur. J. 2016, 22, 9235-9239. [CrossRef]

37. Borovkov, V. Supramolecular chirality in porphyrin chemistry. Symmetry 2014, 6, 256-294. [CrossRef]

38. Ferrand, Y.; Le Maux, P.; Simonneaux, G. Highly enantioselective synthesis of cyclopropylphosphonates catalyzed by chiral ruthenium porphyrins. Org. Lett. 2004, 6, 3211-3214. [CrossRef] [PubMed]

39. Ogoshi, H.; Mizutani, T. Multifunctional and Chiral Porphyrins: Model Receptors for Chiral Recognition. Acc. Chem. Res. 1998, 31, 81-89. [CrossRef]

40. Konishi, K.; Takahata, Y.; Aida, T.; Inoue, S.; Kuroda, R. Chiral N-Substituted Porphyrins Related to Heme Inactivation Products. First Crystallographic Determination of Absolute Stereochemistry and Correlation with Circular Dichroism. J. Am. Chem. Soc. 1993, 115, 1169-1170. [CrossRef]

41. Lee, H.; Hong, K.-I.; Jang, W.-D. Design and applications of molecular probes containing porphyrin derivatives. Coord. Chem. Rev. 2018, 354, 46-73. [CrossRef]

42. Zhang, Z.; Hu, C.; Wang, Y.; Lang, J.-P. Crystallographic and DFT studies on host-guest complexes consisting of zinc bisporphyrinates and 1-phenylethylamine. J. Coord. Chem. 2019, 72, 1156-1170. [CrossRef]

43. Zhuo, C.-C.; Li, L.; Hu, C.-J.; Lang, J.-P. Host-guest assembly for highly sensitive probing of a chiral mono-alcohol with a zinc trisporphyrinate. Sci. Rep. 2017, 7, 3829. [CrossRef]

44. Hu, Q.; Zhuo, C.; Wang, Y.; Hu, C.; Lang, J. Chirality Transfer from Chiral Monoamines to an m-Phthalic Diamide-Linked Zinc Bisporphyrinate with a Benzylamide Substituent. Inorg. Chem. 2017, 56, 10204-10214. [CrossRef]

45. Hu, T.; Hu, C.; Wang, Y.; Young, D.J.; Lang, J.-P. Stoichiometrically controlled chirality inversion in zinc bisporphyrinatemonoamine complexes. Dalt. Trans. 2018, 47, 5503-5512. [CrossRef]

46. Hu, T.; Liu, T.; Zhang, Z.; Wang, Y.; Yang, Y.; Young, D.J.; Hu, C.; Lang, J.-P. Precise control of chirality transfer by adjusting the alkyl substituents of guests. Dye. Pigment. 2019, 160, 692-699. [CrossRef]

47. Hembury, G.A.; Borovkov, V.V.; Inoue, Y. Chirality-sensing supramolecular systems. Chem. Rev. 2008, 108, 1-73. [CrossRef]

48. Zhou, Y.; Yu, B.; Levon, K. Potentiometric sensing of chiral amino acids. Chem. Mater. 2003, 15, 2774-2779. [CrossRef]

49. Cavazzini, A.; Nadalini, G.; Dondi, F.; Gasparrini, F.; Ciogli, A.; Villani, C. Study of mechanisms of chiral discrimination of amino acids and their derivatives on a teicoplanin-based chiral stationary phase. J. Chromatogr. A 2004, 1031, 143-158. [CrossRef]

50. Fu, Y.; Han, Q.; Chen, Q.; Wang, Y.; Zhou, J.; Zhang, Q. A new strategy for chiral recognition of amino acids. Chem. Commun. 2012, 48, 2322-2324. [CrossRef] [PubMed] 
51. Carmo dos Santos, N.A.; Badetti, E.; Licini, G.; Abbate, S.; Longhi, G.; Zonta, C. A stereodynamic fluorescent probe for amino acids. Circular dichroism and circularly polarized luminescence analysis. Chirality 2018, 30, 65-73. [CrossRef] [PubMed]

52. Friedman, M.; Cuq, J.L. Chemistry, analysis, nutritional value, and toxicology of tryptophan in food. A review. J. Agric. Food Chem. 1988, 36, 1079-1093. [CrossRef]

53. Cifuentes, A. Recent advances in the application of capillary electromigration methods for food analysis. Electrophoresis 2006, 27, 283-303. [CrossRef]

54. Herrero, M.; Ibáñez, E.; Martín-Álvarez, P.J.; Cifuentes, A. Analysis of chiral amino acids in conventional and transgenic maize. Anal. Chem. 2007, 79, 5071-5077. [CrossRef]

55. Kuroda, Y.; Kato, Y.; Higashioji, T.; Ogoshi, H. New Chiral Porphyrins-Syntheses and Molecular Recognition of Amino Acid Esters. Angew. Chem. Int. Ed. Engl. 1993, 32, 723-724. [CrossRef]

56. Yasuhisa Kuroda, R.; Kato, Y.; Higashioji, T.; Hasegawa, J.; Kawanami, S.; Takahashi, M.; Shiraishi, N.; Tanabe, K.; Ogoshi, H. Chiral Amino Acid Recognition by a Porphyrin-Based Artificial. J. Am. Chem. Soc 1995, 117, 10950-10958. [CrossRef]

57. Mizutani, E.T.; Ema, T.; Tomita, T.; Kuroda, Y.; Ogoshi, H. Design and Synthesis of a Trifunctional Chiral Porphyrin with C2 Symmetry as a Chiral Recognition Host for Amino Acid. J. Am. Chem. Soc 1994, 116, 4240-4250. [CrossRef]

58. Mizutani, T.; Ema, T.; Yoshida, T.; Kuroda, Y.; Ogoshi, H. Recognition of $\alpha$-Amino Acid Esters by Zinc Porphyrin Derivatives via Coordination and Hydrogen Bonding Interactions. Evidence for Two-Point Fixation from Thermodynamic and Induced Circular Dichroism Spectroscopic Studies. Inorg. Chem. 1993, 32, 2072-2077. [CrossRef]

59. Wang, C.Z.; Zhu, Z.A.; Li, Y.; Chen, Y.T.; Wen, X.; Miao, F.M.; Chan, W.L.; Chan, A.S. Chiral recognition of amino acid esters by zinc porphyrin derivatives. New J. Chem. 2001, 25, 801-806. [CrossRef]

60. Schwenninger, R.; Ramondenc, Y.; Wurst, K.; Schlögl, J.; Kräutler, B. A Highly Enantiopure Biconcave Porphyrin with Effective D4-Structure. Chem. Eur. J. 2000, 6, 1214-1223. [CrossRef]

61. Schwenninger, R.; Schlögl, J.; Maynollo, J.; Gruber, K.; Ochsenbein, P.; Bürgi, H.-B.; Konrat, R.; Kräutler, B. Metal Complexes of a Biconcave Porphyrin with D4-Structure-Versatile Chiral Shift Agents. Chem. Eur. J. 2001, 7, 2676-2686. [CrossRef]

62. Imai, H.; Munakata, H.; Uemori, Y.; Sakura, N. Chiral Recognition of Amino Acids and Dipeptides by a Water-Soluble Zinc Porphyrin. Inorg. Chem. 2004, 43, 1211-1213. [CrossRef]

63. Fa, H.B.; Zhao, L.; Wang, X.Q.; Yu, J.H.; Huang, Y.B.; Yang, M.; Wang, D.J. Chiral recognition of mesoporous SBA-15 with an incorporated chiral porphyrin. Eur. J. Inorg. Chem. 2006, 2006, 4355-4361. [CrossRef]

64. Crossley, M.J.; Hambley, T.W.; MacKay, L.G.; Try, A.C.; Walton, R. Porphyrin analogues of Tröger's base: Large chiral cavities with a bimetallic binding site. J. Chem. Soc. Chem. Commun. 1995, 1077-1079. [CrossRef]

65. Crossley, M.J.; MacKay, L.G.; Try, A.C. Enantioselective recognition of histidine and lysine esters by porphyrin chiral clefts and detection of amino acid conformations in the bound state. J. Chem. Soc. Chem. Commun. 1995, 1925-1927. [CrossRef]

66. Tatar, A.; Valík, M.; Novotná, J.; Havlík, M.; Dolenský, B.; Král, V.; Urbanová, M. Preparation and enantioselectivity binding studies of a new chiral cobalt(II)porphyrin-Tröger's base conjugate. Chirality 2014, 26, 361-367. [CrossRef]

67. Lee, Y.J.; Kang, B.; Seo, J. Metalloporphyrin dimers bridged by a peptoid helix: Host-guest interaction and chiral recognition. Molecules 2018, 23, 2741. [CrossRef] [PubMed]

68. Wang, J.; Zhang, Z.; Hu, C.; Wang, Y. Enantioselectivity of a tartaric acid amide linked zinc bisporphyrinate towards amino acid esters. Dye. Pigment. 2020, 176, 108223. [CrossRef]

69. Wu, X.; Starnes, S.D. L-nipecotic acid-porphyrin derivative: A chiral host with introverted functionality for chiral recognition. Org. Lett. 2012, 14, 3652-3655. [CrossRef]

70. Stefanelli, M.; Magna, G.; Zurlo, F.; Caso, F.M.; Di Bartolomeo, E.; Antonaroli, S.; Venanzi, M.; Paolesse, R.; Di Natale, C.; Monti, D. Chiral Selectivity of Porphyrin-ZnO Nanoparticle Conjugates. ACS Appl. Mater. Interfaces 2019, 11, 12077-12087. [CrossRef]

71. Ballantine, D.S., Jr.; White, R.M.; Martin, S.J.; Ricco, A.J.; Zellers, E.T.; Frye, G.C.; Wohltjen, H. Acoustic Wave Sensors: Theory, Design and Physico-Chemical Applications, 1st ed.; Academic Press: San Diego, CA, USA; Elsevier: San Diego, CA, USA, 1996; ISBN 9780080523330.

72. Ema, T.; Ouchi, N.; Doi, T.; Korenaga, T.; Sakai, T. Highly sensitive chiral shift reagent bearing two zinc porphyrins. Org. Lett. 2005, 7, 3985-3988. [CrossRef]

73. Borovkov, V.V.; Hembury, G.A.; Inoue, Y. Supramolecular chirogenesis with bis-chlorin versus bis-porphyrin hosts: Peculiarities of chirality induction and modulation of optical activity. J. Org. Chem. 2005, 70, 8743-8754. [CrossRef] [PubMed]

74. Borovkov, V.V.; Muranaka, A.; Hembury, G.A.; Origane, Y.; Ponomarev, G.V.; Kobayashi, N.; Inoue, Y. Chiral bis-chlorin: Enantiomer resolution and absolute configuration determination. Org. Lett. 2005, 7, 1015-1018. [CrossRef]

75. Ikeda, T.; Sada, K.; Shinkai, S.; Takeuchi, M. Enantioselective recognition of dicarboxylic acid guests based on an allosteric effect of a chiral double-decker porphyrin which changes the stoichiometry upon the guest binding. Supramol. Chem. 2011, $23,59-64$. [CrossRef]

76. Ema, T.; Ura, N.; Eguchi, K.; Ise, Y.; Sakai, T. Chiral porphyrin dimer with a macrocyclic cavity for intercalation of aromatic guests. Chem. Commun. 2011, 47, 6090-6092. [CrossRef] [PubMed]

77. Kasha, M.; Rawls, H.R.; El-Bayoumi, M.A. The Exciton Model In Molecular Spectroscopy. Pure Appl. Chem. 1965, 11, $371-392$. [CrossRef]

78. Matile, S.; Berova, N.; Nakanishi, K.; Novkova, S.; Philipova, I.; Blagoev, B. Porphyrins: Powerful Chromophores for Structural Studies by Exciton-Coupled Circular Dichroism. J. Am. Chem. Soc. 1995, 117, 7021-7022. [CrossRef] 
79. Berova, N.; Di Bari, L.; Pescitelli, G. Application of electronic circular dichroism in configurational and conformational analysis of organic compounds. Chem. Soc. Rev. 2007, 36, 914. [CrossRef] [PubMed]

80. Lu, W.; Yang, H.; Li, X.; Wang, C.; Zhan, X.; Qi, D.; Bian, Y.; Jiang, J. Chiral Discrimination of Diamines by a Binaphthalene-Bridged Porphyrin Dimer. Inorg. Chem. 2017, 56, 8223-8231. [CrossRef] [PubMed]

81. Saha, B.; Ikbal, S.A.; Rath, S.P. Complexation of Chiral Zinc(II)Porphyrin Tweezer with Chiral Guests: Control, Discrimination and Rationalization of Supramolecular Chirality. Inorg. Chem. 2020, 59, 7795-7809. [CrossRef] [PubMed]

82. Gilissen, P.J.; Slootbeek, A.D.; Ouyang, J.; Vanthuyne, N.; Bakker, R.; Elemans, J.A.A.W.; Nolte, R.J.M. Enantioselective synthesis of chiral porphyrin macrocyclic hosts and kinetic enantiorecognition of viologen guests. Chem. Sci. 2021, 12, 1661-1667. [CrossRef]

83. Easson, L.H.; Stedman, E. Studies on the relationship between chemical constitution and physiological action. Biochem. J. 1933, 27, 1257-1266. [CrossRef] [PubMed]

84. Ogston, A.G. Interpretation of experiments on metabolic processes, using isotopic tracer elements [9]. Nature 1949, 163, 963. [CrossRef] [PubMed]

85. Berthod, A. Chiral recognition mechanisms. Anal. Chem. 2006, 78, 2093-2099. [CrossRef] [PubMed] 